\title{
Relationship between red cell storage duration and outcomes in adults receiving red cell transfusions: a systematic review
}

\author{
Christophe Lelubre and Jean-Louis Vincent ${ }^{*}$
}

\begin{abstract}
Introduction: The duration of red blood cell (RBC) storage before transfusion may alter RBC function and supernatant and, therefore, influence the incidence of complications or even mortality.

Methods: A MEDLINE search from 1983 to December 2012 was performed to identify studies reporting age of transfused RBCs and mortality or morbidity in adult patients.

Results: Fifty-five studies were identified; most were single-center (93\%) and retrospective (64\%), with only a few, small randomized studies (eight studies, 14.5\%). The numbers of subjects included ranged from eight to 364,037. Morbidity outcomes included hospital and intensive care unit (ICU) length of stay (LOS), infections, multiple organ failure, microcirculatory alterations, cancer recurrence, thrombosis, bleeding, vasospasm after subarachnoid hemorrhage, and cognitive dysfunction. Overall, half of the studies showed no deleterious effects of aged compared to fresh blood on any endpoint. Eleven of twenty-two (50\%) studies reported no increased mortality, three of nine (33\%) showed no increased LOS with older RBCs and eight of twelve (66\%) studies showed no increased risks of organ failure. Ten of eighteen (55\%) studies showed increased infections with transfusion of older RBCs. The considerable heterogeneity among studies and numerous methodological flaws precluded a formal meta-analysis.
\end{abstract}

Conclusions: In this systematic review, we could find no definitive argument to support the superiority of fresh over older RBCs for transfusion.

\section{Introduction}

Red blood cell (RBC) transfusions are one of the most common medical interventions [1]. Although they can be lifesaving, RBC transfusions have come under intense scrutiny over the last few decades [2]. In a recent review of 45 observational studies that had reported the impact of transfusion on outcomes in different patient groups (trauma; general, cardiac, orthopedic and neurosurgical; acute coronary syndrome; intensive care (ICU) patients), $\mathrm{RBC}$ transfusion was an independent predictor of death, infectious complications and acute respiratory distress syndrome (ARDS) [3].

The 'storage lesion' refers to the multiple complex biochemical and biomechanical alterations that occur during ex vivo storage, modifying $\mathrm{RBC}$ properties and the

\footnotetext{
* Correspondence: jlvincen@ulb.ac.be

Department of Intensive Care, Erasme Hospital, Université Libre de Bruxelles, Route de Lennik 808, 1070 Brussels, Belgium
}

supernatant [4] (Table 1). A progressive decrease in 2,3diphosphoglycerate (DPG) levels may impair oxygen delivery [5], and a decreased adenosine triphosphate (ATP) pool reduces $\mathrm{Na}^{+}-\mathrm{K}^{+}$-ATPase activity and, possibly, ATPmediated hypoxic vasodilation. Decreased antioxidant capacities of the erythrocyte may alter reduction of methemoglobin [6], generating reactive oxygen species (ROS) through the Fenton reaction. Complex, irreversible membrane changes (including alterations in protein band 3 [7] and release of procoagulant [8] vesicles) lead to poorly deformable sphero-echinocytes with increased adherence to the endothelium [9] and increased susceptibility to phagocytosis [10]. Changes also occur in the supernatant, with a progressive decrease in $\mathrm{pH}$, increased potassium concentration, and release of proinflammatory molecules, complement or biologically active lipids (platelet-activating factor). Release of hemoglobin (free or contained in microparticles) may scavenge nitric oxide (NO) in the transfusion recipient and lead to vasoconstriction [11] and iron 
Table 1 Main components of the storage lesion.

\begin{tabular}{|c|c|}
\hline Changes occurring to the RBC & Changes occurring in the supernatant \\
\hline Metabolic changes & \\
\hline $\begin{array}{c}\text { - Decreased 2-3 DPG, possibly with impaired oxygen delivery [5] } \\
\text { - Decreased phosphate and adenine pool (AMP, ADP, ATP) [24] } \\
\text { - Decreased glutathione levels [6] } \\
\text { - Decreased S-nitroso hemoglobin [110] } \\
\cdot \text { Increased lactate levels }\end{array}$ & $\begin{array}{c}\text { • Decreased pH } \\
\text { - Increased potassium concentrations (decreased Na-K-ATPase activity) } \\
\text { with increased risks of hyperkalemia } \\
\text { • Release of various molecules: } \\
\text { o Proinflammatory cytokines (IL-1 beta, IL-6, IL-8, TNF-alpha) and } \\
\text { complement } \\
\text { - Biologically active lipids such as platelet-activating factor (PAF) [14] } \\
\text { o Free hemoglobin prone to scavenge nitric oxide (NO) of the } \\
\text { recipient (together with Hb-containing microparticles) [109] } \\
\text { o Heme and iron [12] with potential redox injuries, cytotoxicity and } \\
\text { inflammation }\end{array}$ \\
\hline
\end{tabular}

Oxidative stress

- Protein oxidation including cytoskeleton [111]

- Lipid peroxidation, generation of lysophospholipids prone to cause cases of TRALI, generation of prostaglandins and isoprostanes [112]

Shape and membrane changes

- Shift from early reversible echinocytes to irreversible sphero-echinocytes - Generation of microvesicles with procoagulant properties

- Increased RBC rigidity and adherence to vascular endothelium²

- Decreased CD47 expression, increased phosphatidylserine exposure

ADP, adenosine diphosphate; AMP, adenosine monophosphate; ATP, adenosine triphosphate; DPG, diphosphoglycerate; Hb, hemoglobin; IL, interleukin; RBC, red blood cell; TNF-alpha, tumor necrosis factor alpha; TRALI, transfusion-related acute lung injury.

and heme may generate redox injuries, cytotoxicity and inflammation $[12,13]$. RBCs prone to increased oxidative injury undergo protein and lipid peroxidation with release of lysophospholipids, which may cause transfusion-associated acute lung injury (ALI) [14]. However, animal models describing altered blood flow following transfusion of old RBCs $[15,16]$ may be of limited relevance to humans [17]. Some alterations described ex vivo, such as the decreases in 2,3-DPG or ATP levels, may be at least partly reversible after transfusion [17]. Therefore, the impact of storage lesions observed in vitro may not be relevant clinically $[18,19]$. Some recent meta-analyses [20-22] have been attempted, but the heterogeneity and methodological limitations of the studies included prevented definitive conclusions. The duration of RBC storage varies among units. Large observational studies have reported a mean duration of RBC storage of between 16 and 21 days [23], with a maximum storage duration before transfusion being generally limited to 42 days (with standard preservative solutions). However, the regulatory requirements for this limit are based only on the percentage $\mathrm{RBC}$ survival $24 \mathrm{~h}$ after transfusion (which has to be $\geq 75 \%$ ), not on oxygen delivery capacities or clinical endpoints [24].

The aim of this article was to review the clinical evidence related to the potential impact of RBC storage on outcomes in adult patients.

\section{Materials and methods}

A MEDLINE search (accessed through Pubmed and Ovid) of the literature was performed to identify studies in adult patients that linked the duration of storage of transfused
RBCs with physiologic variables (oxygen consumption, alterations of microcirculation), morbidity and mortality. Morbidity outcomes included infection; postoperative bleeding; thrombosis, including myocardial infarction; duration of mechanical ventilation; multiple organ dysfunction including acute renal failure; ICU and hospital lengths of stay (LOS); and other less common endpoints, such as cancer recurrence, vasospasm after subarachnoid hemorrhage (SAH) or cognitive dysfunction. Medical Subject Headings (MeSH) terms ('Erythrocytes', 'Blood Transfusion', 'Mortality', 'Infection', 'Pneumonia', 'Acute Kidney Injury', 'Length of Stay', 'Multiple Organ Failure', 'Respiration, Artificial', 'Venous Thrombosis', 'Neoplasms', 'Microcirculation', 'Oxygen Consumption', 'Vasospasm, Intracranial') and non-MeSH terms ('Age', 'Storage', 'Duration') were used for the search process. All studies on adult patients (more than 19 years old) published from 1983 to December 2012 (last access, December 15, 2012) and written in any language were selected for individual screening. The Cochrane Library was searched using the same search strategy. Bibliographic references of relevant studies were also checked manually to complete the search process. Review articles, editorials, meta-analyses, abstracts of scientific meetings or studies that were subsequently retracted were not included. The flow diagram related to the search process is shown in Figure 1 according to the PRISMA statement [25]. Once selected, additional data regarding potential confounders (for example, data on leukoreduction status) were collected, and studies were grouped according to their primary outcome measure for qualitative synthesis. Given their particular importance in causal inference, 


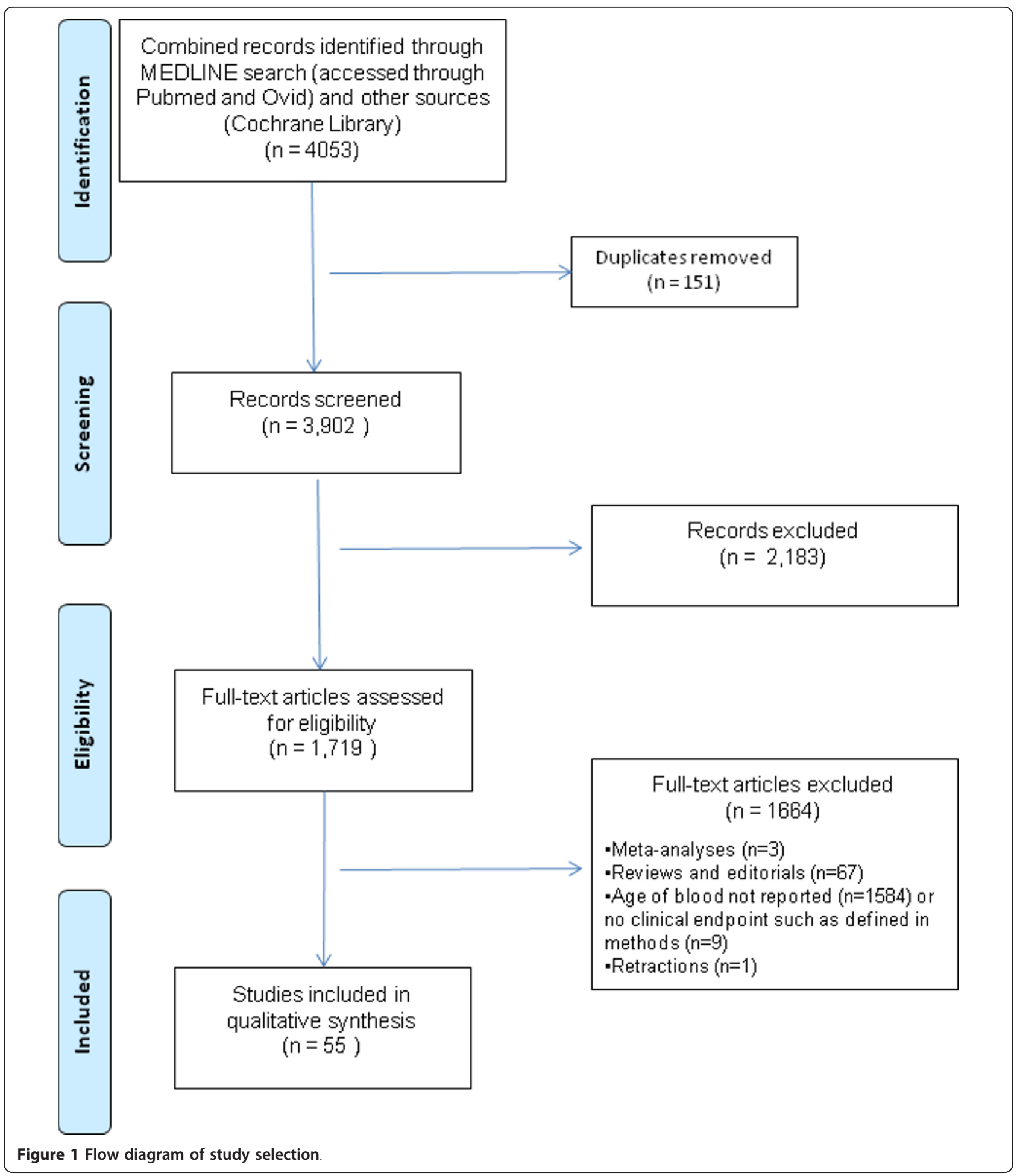

randomized controlled trials (RCTs) were also considered separately.

Mean values are given $+/$ - standard deviation (SD) and median values are given with interquartile ranges (IQR). All relative risks (RR), odds ratios (OR) or hazard ratios (HR) are provided with 95\% confidence intervals (CI).

\section{Results}

The search process retrieved 4,053 (3,902 after duplicate removal) studies, of which 2,183 were excluded, leaving 1,719 studies that were assessed for eligibility (Figure 1). Of these, 1,664 were excluded for various reasons (reviews and editorials, meta-analyses, subsequent 
retraction of one study on cardiac surgery patients $[26,27]$, and studies not reporting RBC storage variables or no clinical endpoint as defined earlier). Accordingly, the analysis included 55 studies (Table 2), with a total of 407,185 patients. Most studies were retrospective $(n=$ $35,64 \%)$ and single-center $(n=51,93 \%)$. The number of transfused subjects ranged from eight to 364,037 (median: 268 patients, IQR: 61 to 757 ). Only a small proportion of the studies were randomized trials $(n=8$, 14.5\%); the eight randomized studies had fewer included patients (median $=21$ patients, IQR: 10.5 to 83.75 ) and, in the majority, physiological variables were reported as the primary outcome measure ( $n=6$ studies) (Table 3).

\section{Effect on mortality}

We identified 22 studies that reported mortality as an endpoint, 20 of which were retrospective. Six studies focused on trauma patients, five on cardiac surgery patients, four on ICU patients and seven on mixed or other populations (patients with colorectal cancer, patients with cardiovascular disease or undergoing percutaneous coronary intervention, patients receiving hematopoietic stem cell transplantation or undergoing liver transplantation). Among these 22 studies, only one was a randomized trial, but this single-center study was small and not primarily powered for mortality [28]. In this trial conducted on 100 mechanically ventilated ICU patients, patients randomized to exclusively receive fresh RBCs ( $n=50$, median RBC age: 4.0 days) had similar mortality rates $36 \%$ in the fresh group vs. $40 \%$ in the standard issue group, $P=0.41$ ) than those receiving standard RBCs ( $n=50$, median RBC age: 26.5 days) [28]. We identified one prospective, observational study, an Australian multicenter study of 757 critically ill patients (including a mix of medical and surgical patients) in which exposure to the highest age quartile of RBCs (average age: 17.6 days) was associated with a significantly higher hospital mortality rate compared to lowest quartile (average age: 7.5 days) RBCs, even after correction for disease severity (APACHE III score) and the number of units transfused (OR: 2.01 (1.07 to 3.77), $P=0.03$ ) [29].

The largest study to date exploring the association between age of transfused RBCs and mortality comes from the Swedish/Danish SCANDAT database exploring 404,959 transfusion episodes in more than 300,000 (mainly trauma and surgical) patients from 1995 to 2002: administration of RBCs aged 30 to 42 days was associated with a $5 \%$ increased mortality (HR: 1.05; 95\% CI, 1.02 to 1.08) after two years of follow-up [30], but the authors acknowledged that this risk could have been overestimated in view of a greater baseline risk in recipients of older units. In another retrospective, registry-based analysis of 6,994 surgical patients with comorbidities (ASA score more than III in $80 \%$ of patients; cardiac surgery patients excluded) receiving a median of two leukoreduced RBC units, Saager et al. found no relationship between median RBC storage duration and postoperative mortality (up to two years) in a Cox regression model (adjusting for $\mathrm{ABO}$ group and number of units transfused) [31].

Some studies included more homogeneous patient populations. In cardiac surgery patients, the largest study was a single-center, retrospective study of 6,002 patients undergoing coronary artery bypass graft (CABG), valve surgery or both. Patients transfused with older blood (median: 20 days) had greater hospital mortality compared to those receiving fresher (median: 11 days) blood (2.8\% vs. $1.7 \%, P=0.004)$. Patients transfused with older blood also had a higher one-year mortality rate (11.0 vs. $7.4 \%$, $P<0.001$ ) [32]. However, these results were much debated and challenged by other groups that were unable to find such an association [33-37]. In a single-center study of 2,732 patients undergoing CABG, van de Watering et al. [38] found no correlation between storage time variables and 30-day mortality in adjusted multivariate analyses. In this study, 30-day mortality was similar in patients receiving exclusively older (mean: $24.3+/-3.5$ days) or younger RBCs (mean: $12.7+/-2.8$ days). In a retrospective study of 1,153 cardiac surgery patients, McKenny et al. [39] found no association between RBC storage duration and postoperative mortality in a multivariate analysis. In another retrospective, single-center study of 3,597 patients with isolated CABG, van Straten et al. [40] found no effect of $\mathrm{RBC}$ storage duration on early or late postoperative mortality. In a single-center, retrospective cohort study of 670 patients undergoing CABG and/or valve surgery, Yap and coworkers also found no association between storage duration and mortality [41].

Two retrospective studies examined the association of RBC storage with mortality in critically ill patients. The first was a small cohort of 31 septic patients in which non-survivors received a greater proportion of older RBCs (> 20 days old) compared to survivors, who received a greater proportion of younger RBCs $(<10$ days old) [42]. In another retrospective, single-center study of 534 general ICU patients, there was no association between the age of transfused red cells (median of maximum age of RBCs: 23 days) and mortality in multivariate analyses [43].

We found six studies with mortality as an outcome in trauma patients. In a retrospective cohort study of 1,813 severe trauma patients (mean Injury Severity Score (ISS) 26), transfusion of large (but not small) volumes of older blood (more than 14 days old) was associated with an increased risk of death compared to transfusion of the same volumes of younger blood $(<14$ days old), suggesting that the age of transfused RBCs could potentiate the already known association between volume of blood 
Table 2 Overview of the studies reporting the age of transfused red blood cells (RBCs) and patient outcomes.

\begin{tabular}{|c|c|c|c|c|c|c|c|c|}
\hline First author & Year & $\begin{array}{l}\text { Year(s) of } \\
\text { enrollment }\end{array}$ & Design & $\begin{array}{l}\text { Country/ } \\
\text { continent }\end{array}$ & $\begin{array}{l}\text { Leuko- } \\
\text { reduction }\end{array}$ & Setting & $\begin{array}{l}\text { Number } \\
\text { of } \\
\text { patients } \\
\text { transfused }\end{array}$ & Summary of main results \\
\hline \multicolumn{9}{|c|}{ Studies addressing mortality } \\
\hline Purdy et al. [42] & 1997 & 1992 & $\begin{array}{l}\text { Retrospective } \\
\text { single-center }\end{array}$ & Canada & NR & ICU septic & 31 & $\begin{array}{l}\text { Non-survivors received a greater } \\
\text { proportion of older RBCs }\end{array}$ \\
\hline Mynster et al. [53] & 2001 & 1991-1993 & $\begin{array}{l}\text { Retrospective } \\
\text { multicenter }\end{array}$ & Europe & No & Cancer & 740 & $\begin{array}{c}\text { Mortality not different between } \\
\text { patients transfused with RBCs aged } \\
\text { more or less than } 21 \text { days }\end{array}$ \\
\hline Murrell et al. [48] & 2005 & 2001-2003 & $\begin{array}{l}\text { Retrospective } \\
\text { single-center }\end{array}$ & USA & $\begin{array}{l}\text { Mix }(95 \% \\
\text { LR) }\end{array}$ & Trauma & 275 & $\begin{array}{l}\text { No correlation between 'dose of aged } \\
\text { blood' and hospital mortality }\end{array}$ \\
\hline $\begin{array}{l}\text { van de Watering } \\
\text { et al. [38] }\end{array}$ & 2006 & 1993-1999 & $\begin{array}{l}\text { Retrospective } \\
\text { single-center }\end{array}$ & Europe & No & $\begin{array}{l}\text { Cardiac } \\
\text { surgery }\end{array}$ & 2,732 & $\begin{array}{l}\text { No correlation between storage time } \\
\text { variables and 30-day mortality }\end{array}$ \\
\hline Koch et al. [32] & 2008 & 1998-2006 & $\begin{array}{l}\text { Retrospective } \\
\text { single-center }\end{array}$ & USA & Mix & $\begin{array}{l}\text { Cardiac } \\
\text { surgery }\end{array}$ & 6,002 & $\begin{array}{l}\text { Higher hospital and one-year mortality } \\
\text { rate in older blood group }\end{array}$ \\
\hline Yap et al. [41] & 2008 & 2001-2007 & $\begin{array}{l}\text { Retrospective } \\
\text { single-center }\end{array}$ & Australia & $\begin{array}{l}\text { Mix }(3.8 \% \\
\quad \text { LR) }\end{array}$ & $\begin{array}{l}\text { Cardiac } \\
\text { surgery }\end{array}$ & 670 & $\begin{array}{l}\text { No association between storage } \\
\text { duration and mortality }\end{array}$ \\
\hline $\begin{array}{c}\text { Dessertaine et al. } \\
\text { [43] }\end{array}$ & 2008 & 2005-2006 & $\begin{array}{l}\text { Retrospective } \\
\text { single-center }\end{array}$ & Europe & Yes & ICU & 534 & $\begin{array}{l}\text { No association between the age of } \\
\text { transfused red cells and mortality }\end{array}$ \\
\hline $\begin{array}{l}\text { Weinberg et al. } \\
{[44]}\end{array}$ & 2008 & 2000-2007 & $\begin{array}{l}\text { Retrospective } \\
\text { single-center }\end{array}$ & USA & Yes & Trauma & 1,813 & $\begin{array}{l}\text { Transfusion of large (but not small) } \\
\text { volumes of older blood associated } \\
\text { with an increased risk of death }\end{array}$ \\
\hline $\begin{array}{c}\text { Weinberg et al. } \\
{[46]}\end{array}$ & 2008 & 2000-2007 & $\begin{array}{l}\text { Retrospective } \\
\text { single-center }\end{array}$ & USA & Yes & Trauma & 430 & $\begin{array}{c}\text { Slightly increased mortality with } \\
\text { transfusion of older blood (> } 14 \text { days } \\
\text { old) }\end{array}$ \\
\hline Spinella et al. [47] & 2009 & $2004-2007$ & $\begin{array}{l}\text { Retrospective } \\
\text { single-center }\end{array}$ & USA & Mix & Trauma & 202 & $\begin{array}{l}\text { Hospital mortality higher for patients } \\
\text { transfused with older RBCs; increased } \\
\text { storage time independently associated } \\
\text { with mortality }\end{array}$ \\
\hline Edgren et al. [30] & 2010 & 1995-2002 & $\begin{array}{l}\text { Retrospective } \\
\text { multicenter }\end{array}$ & Europe & Mix & Mix & 364,037 & $\begin{array}{l}5 \% \text { increased mortality after two years } \\
\text { of follow-up }\end{array}$ \\
\hline $\begin{array}{l}\text { Weinberg et al. } \\
{[45]}\end{array}$ & 2010 & 2000-2009 & $\begin{array}{l}\text { Retrospective } \\
\text { single-center }\end{array}$ & USA & Yes & Trauma & 1,647 & $\begin{array}{l}\text { Trend toward higher mortality rate } \\
\text { with older blood when transfused } \\
\text { more than three RBC units }\end{array}$ \\
\hline $\begin{array}{l}\text { Eikelboom et al. } \\
{[50]}\end{array}$ & 2010 & $2002-2006$ & $\begin{array}{l}\text { Retrospective } \\
\text { single-center }\end{array}$ & Canada & Yes & $\begin{array}{l}\text { Cardiovascular } \\
\text { disease }\end{array}$ & 4,933 & $\begin{array}{l}\text { Greater risk of hospital mortality in the } \\
\text { highest age quartile of RBCs }\end{array}$ \\
\hline $\begin{array}{l}\text { Robinson et al. } \\
\text { [51] }\end{array}$ & 2010 & 1999-2005 & $\begin{array}{l}\text { Retrospective } \\
\text { single-center }\end{array}$ & Canada & NR & $\mathrm{PCl}$ & 909 & $\begin{array}{l}\text { Storage duration associated with 30- } \\
\text { day mortality }\end{array}$ \\
\hline $\begin{array}{c}\text { van Straten et al. } \\
{[40]}\end{array}$ & 2011 & 1998-2007 & $\begin{array}{l}\text { Retrospective } \\
\text { single-center }\end{array}$ & Europe & Yes & $\begin{array}{l}\text { Cardiac } \\
\text { surgery }\end{array}$ & 3,597 & $\begin{array}{l}\text { No effect of RBC storage duration on } \\
\text { early or late postoperative mortality }\end{array}$ \\
\hline $\begin{array}{l}\text { Mckenny et al. } \\
{[39]}\end{array}$ & 2011 & $2002-2007$ & $\begin{array}{l}\text { Retrospective } \\
\text { single-center }\end{array}$ & Europe & Yes & $\begin{array}{l}\text { Cardiac } \\
\text { surgery }\end{array}$ & 1,153 & $\begin{array}{l}\text { No association between RBC storage } \\
\text { duration and postoperative mortality }\end{array}$ \\
\hline Kekre et al. [54] & 2011 & $2002-2007$ & $\begin{array}{l}\text { Retrospective } \\
\text { single-center }\end{array}$ & Canada & Yes & $\mathrm{HSCT}$ & 555 & $\begin{array}{l}\text { Non-relapse } 100-\text { day mortality } \\
\text { reduced in the subgroup of patients } \\
\text { receiving exclusively old blood (>14 } \\
\text { days old) }\end{array}$ \\
\hline Pettila et al. [29] & 2011 & 2008 & $\begin{array}{l}\text { Prospective, } \\
\text { multicenter }\end{array}$ & $\begin{array}{l}\text { Australia - } \\
\text { New } \\
\text { Zealand }\end{array}$ & Mix & ICU & 757 & $\begin{array}{l}\text { Exposure to the highest age quartile } \\
\text { of RBCs associated with a higher } \\
\text { hospital mortality rate compared to } \\
\text { lowest quartile }\end{array}$ \\
\hline Hassan et al. [49] & 2011 & 2003-2005 & $\begin{array}{l}\text { Retrospective } \\
\text { single-center }\end{array}$ & USA & NR & Trauma & 820 & $\begin{array}{c}\text { Number of older units not associated } \\
\text { with increased mortality }\end{array}$ \\
\hline Saager et al. [31] & 2012 & 2005-2009 & $\begin{array}{l}\text { Retrospective } \\
\text { single-center }\end{array}$ & USA & Yes & $\begin{array}{l}\text { Non-cardiac } \\
\text { surgery }\end{array}$ & 6,994 & $\begin{array}{l}\text { No relationship between median RBC } \\
\text { storage duration and postoperative } \\
\text { mortality (up to two years) }\end{array}$ \\
\hline Dunn et al. [52] & 2012 & $2000-2010$ & $\begin{array}{l}\text { Retrospective } \\
\text { single-center }\end{array}$ & USA & NR & $\begin{array}{l}\text { Liver } \\
\text { transplant }\end{array}$ & 509 & $\begin{array}{c}\text { Transfusion of older blood not } \\
\text { associated with increased two-year } \\
\text { mortality }\end{array}$ \\
\hline
\end{tabular}


Table 2 Overview of the studies reporting the age of transfused red blood cells (RBCs) and patient outcomes. (Continued)

\begin{tabular}{|c|c|c|c|c|c|c|c|c|}
\hline Kor et al. [28] & 2012 & $2008-2010$ & $\begin{array}{l}\text { Randomized } \\
\text { single-center } \\
\text { study }\end{array}$ & USA & Yes & $\mathrm{ICU}$ & 100 & $\begin{array}{l}\text { Similar mortality between fresh and } \\
\text { standard issue RBCs but not powered } \\
\text { for this outcome }\end{array}$ \\
\hline \multicolumn{9}{|c|}{ Studies addressing ICU or hospital length of stay } \\
\hline $\begin{array}{c}\text { Vamvakas et al. } \\
{[56]}\end{array}$ & 2000 & 1995 & $\begin{array}{l}\text { Retrospective } \\
\text { single-center }\end{array}$ & USA & $\begin{array}{l}\text { Mix } \\
\text { (mostly } \\
\text { not) }\end{array}$ & $\begin{array}{l}\text { Cardiac } \\
\text { surgery }\end{array}$ & 268 & $\begin{array}{c}\text { No association between RBC storage } \\
\text { duration and postoperative ICU and } \\
\text { hospital LOS }\end{array}$ \\
\hline Keller et al. [58] & 2002 & 1998-1999 & $\begin{array}{l}\text { Retrospective } \\
\text { single-center }\end{array}$ & USA & No & Trauma & 86 & $\begin{array}{c}\text { Number of units of blood older than } \\
14 \text { days associated with an increased } \\
\text { hospital LOS }\end{array}$ \\
\hline $\begin{array}{l}\text { Leal-Noval et al. } \\
{[55]}\end{array}$ & 2003 & $1998-2000$ & $\begin{array}{l}\text { Prospective } \\
\text { single-center }\end{array}$ & Europe & No & $\begin{array}{l}\text { Cardiac } \\
\text { surgery }\end{array}$ & 585 & $\begin{array}{l}\text { No association between mean } \\
\text { duration of RBC storage and ICU LOS }\end{array}$ \\
\hline Murrell et al. [48] & 2005 & $2001-2003$ & $\begin{array}{l}\text { Retrospective } \\
\text { single-center }\end{array}$ & USA & $\begin{array}{l}\text { Mix }(95 \% \\
\text { LR) }\end{array}$ & Trauma & 275 & $\begin{array}{l}\text { Association between 'dose of aged } \\
\text { blood' and ICU LOS }\end{array}$ \\
\hline $\begin{array}{l}\text { van de Watering } \\
\text { et al. [38] }\end{array}$ & 2006 & 1993-1999 & $\begin{array}{l}\text { Retrospective } \\
\text { single-center }\end{array}$ & Europe & No & $\begin{array}{l}\text { Cardiac } \\
\text { surgery }\end{array}$ & 2,732 & $\begin{array}{c}\text { No correlation between storage time } \\
\text { variables and ICU LOS }\end{array}$ \\
\hline Yap et al. [41] & 2008 & $2001-2007$ & $\begin{array}{l}\text { Retrospective } \\
\text { single-center }\end{array}$ & Australia & $\begin{array}{l}\text { Mix }(3.8 \% \\
\quad \text { LR) }\end{array}$ & $\begin{array}{l}\text { Cardiac } \\
\text { surgery }\end{array}$ & 670 & $\begin{array}{c}\text { No association between length of } \\
\text { storage and ICU LOS }\end{array}$ \\
\hline $\begin{array}{l}\text { McKenny et al. } \\
{[39]}\end{array}$ & 2011 & $2002-2007$ & $\begin{array}{l}\text { Retrospective } \\
\text { single-center }\end{array}$ & Europe & Yes & $\begin{array}{l}\text { Cardiac } \\
\text { surgery }\end{array}$ & 1,153 & $\begin{array}{l}\text { No association between length of } \\
\text { storage and ICU LOS }\end{array}$ \\
\hline Sanders et al. [57] & 2011 & $2005-2007$ & $\begin{array}{l}\text { Retrospective } \\
\text { single-center }\end{array}$ & Europe & Yes & $\begin{array}{l}\text { Cardiac } \\
\text { surgery }\end{array}$ & 444 & $\begin{array}{c}\text { Age of blood was a significant but } \\
\text { modest predictor of postoperative } \\
\text { LOS }\end{array}$ \\
\hline Kekre et al. [54] & 2011 & $2002-2007$ & $\begin{array}{l}\text { Retrospective } \\
\text { single-center }\end{array}$ & Canada & Yes & HSCT & 555 & $\begin{array}{l}\text { No correlation between age of } \\
\text { transfused RBCS and hospital LOS }\end{array}$ \\
\hline \multicolumn{9}{|c|}{ Studies addressing age of transfused RBCs and occurrence of infections } \\
\hline Edna et al. [61] & 1998 & 1980-1992 & $\begin{array}{l}\text { Retrospective } \\
\text { single-center }\end{array}$ & Europe & No & Cancer & 240 & $\begin{array}{c}\text { Age of RBCs not different in subjects } \\
\text { developing postoperative infections } \\
\text { and those who did not }\end{array}$ \\
\hline $\begin{array}{c}\text { Vamvakas et al. } \\
{[59]}\end{array}$ & 1999 & 1995 & $\begin{array}{l}\text { Retrospective } \\
\text { single-center }\end{array}$ & USA & Mix & $\begin{array}{l}\text { Cardiac } \\
\text { surgery }\end{array}$ & 256 & $\begin{array}{l}\text { Independent relationship between the } \\
\text { age of transfused RBCs and the } \\
\text { incidence of postoperative pneumonia } \\
\text { or wound infection }\end{array}$ \\
\hline Mynster et al. [53] & 2001 & 1991-1993 & $\begin{array}{l}\text { Retrospective } \\
\text { multicenter }\end{array}$ & Europe & No & Cancer & 740 & $\begin{array}{c}\text { Increased risks of postoperative } \\
\text { infections with transfusions of RBCs } \\
\text { aged } 20 \text { days or more }\end{array}$ \\
\hline Offner et al. [64] & 2002 & 1992- & $\begin{array}{l}\text { Retrospective } \\
\text { single-center }\end{array}$ & USA & No & Trauma & 61 & $\begin{array}{c}\text { Number of units older than } 14 \text { and } 21 \\
\text { days as an independent risk factor for } \\
\text { major infections }\end{array}$ \\
\hline $\begin{array}{c}\text { Leal-Noval et al. } \\
{[55]}\end{array}$ & 2003 & $1998-2000$ & $\begin{array}{l}\text { Prospective } \\
\text { single-center }\end{array}$ & Europe & No & $\begin{array}{l}\text { Cardiac } \\
\text { surgery }\end{array}$ & 585 & $\begin{array}{l}\text { Independent relation between the } \\
\text { oldest RBC unit and postoperative } \\
\text { pneumonia }\end{array}$ \\
\hline Taylor et al. [66] & 2006 & $2001-2003$ & Prospective & USA & Mix & $\mathrm{ICU}$ & 449 & $\begin{array}{c}\text { Maximum age of transfused RBCs not } \\
\text { associated with increased risks of } \\
\text { nosocomial infections }\end{array}$ \\
\hline Koch et al. [32] & 2008 & 1998-2006 & $\begin{array}{l}\text { Retrospective } \\
\text { single-center }\end{array}$ & USA & Mix & $\begin{array}{l}\text { Cardiac } \\
\text { surgery }\end{array}$ & 6,002 & $\begin{array}{l}\text { Higher rates of postoperative sepsis or } \\
\text { septicemia (but not pneumonia or } \\
\text { wound infections) with older RBCs }\end{array}$ \\
\hline $\begin{array}{c}\text { Weinberg et al. } \\
{[46]}\end{array}$ & 2008 & $2000-2007$ & $\begin{array}{l}\text { Retrospective } \\
\text { single-center }\end{array}$ & USA & Yes & Trauma & 430 & $\begin{array}{l}\text { Occurrence of pneumonia related to } \\
\text { the volume of old blood (> } 14 \text { days } \\
\text { old) transfused }\end{array}$ \\
\hline Yap et al. [41] & 2008 & $2001-2007$ & $\begin{array}{l}\text { Retrospective } \\
\text { single-center }\end{array}$ & Australia & $\begin{array}{l}\text { Mix }(3.8 \% \\
\quad \text { LR) }\end{array}$ & $\begin{array}{l}\text { Cardiac } \\
\text { surgery }\end{array}$ & 670 & $\begin{array}{l}\text { No association between storage of } \\
\text { RBCs and postoperative pneumonia }\end{array}$ \\
\hline $\begin{array}{c}\text { Dessertaine et al. } \\
\text { [43] }\end{array}$ & 2008 & $2005-2006$ & $\begin{array}{l}\text { Retrospective } \\
\text { single-center }\end{array}$ & Europe & Yes & $\mathrm{ICU}$ & 534 & $\begin{array}{c}\text { No independent association between } \\
\text { the age of RBCs and nosocomial } \\
\text { infections }\end{array}$ \\
\hline
\end{tabular}


Table 2 Overview of the studies reporting the age of transfused red blood cells (RBCs) and patient outcomes. (Continued)

\begin{tabular}{|c|c|c|c|c|c|c|c|c|}
\hline $\begin{array}{l}\text { Vandromme et al. } \\
{[63]}\end{array}$ & 2009 & 2004-2007 & $\begin{array}{l}\text { Retrospective } \\
\text { single-center }\end{array}$ & USA & Yes & Trauma & 1,183 & $\begin{array}{c}\text { Increased risks of pneumonia after } \\
\text { transfusion of exclusively old RBCs (> } \\
14 \text { days) }\end{array}$ \\
\hline Basora et al. [113] & 2010 & 2004-2005 & $\begin{array}{l}\text { Retrospective } \\
\text { single-center }\end{array}$ & Europe & Yes & $\begin{array}{l}\text { Knee } \\
\text { arthroplasty }\end{array}$ & 335 & $\begin{array}{c}\text { No independent association between } \\
\text { age of transfused RBCs and } \\
\text { postoperative wound infection }\end{array}$ \\
\hline $\begin{array}{l}\text { McKenny et al. } \\
\text { [39] }\end{array}$ & 2011 & $2002-2007$ & $\begin{array}{l}\text { Retrospective } \\
\text { single-center }\end{array}$ & Europe & Yes & $\begin{array}{l}\text { Cardiac } \\
\text { surgery }\end{array}$ & 1,153 & $\begin{array}{l}\text { No association between storage of } \\
\text { RBCs and postoperative pneumonia }\end{array}$ \\
\hline $\begin{array}{c}\text { Andreasen et al. } \\
{[60]}\end{array}$ & 2011 & $2003-2008$ & $\begin{array}{l}\text { Retrospective } \\
\text { multicenter }\end{array}$ & Europe & No & $\begin{array}{l}\text { Cardiac } \\
\text { surgery }\end{array}$ & 1,748 & $\begin{array}{c}\text { Greater risk of postoperative wound } \\
\text { infections and septicemia with RBCs } \\
\text { older than } 14 \text { days }\end{array}$ \\
\hline Hassan et al. [49] & 2011 & 2003-2005 & $\begin{array}{l}\text { Retrospective } \\
\text { single-center }\end{array}$ & USA & NR & Trauma & 820 & $\begin{array}{l}\text { Number of units older than } 14 \text { days as } \\
\text { a significant risk factor for severe } \\
\text { sepsis or septic shock }\end{array}$ \\
\hline $\begin{array}{c}\text { Juffermans et al. } \\
{[67]}\end{array}$ & 2011 & $2004-2007$ & $\begin{array}{l}\text { Retrospective } \\
\text { single-center }\end{array}$ & Europe & Yes & ICU septic & 67 & $\begin{array}{l}\text { Storage time as a confounder for the } \\
\text { association of RBCs with infection }\end{array}$ \\
\hline $\begin{array}{c}\text { Juffermans et al. } \\
\text { [65] }\end{array}$ & 2012 & 2004-2007 & $\begin{array}{l}\text { Retrospective } \\
\text { single-center }\end{array}$ & Europe & Yes & Trauma/TBI & 196 & $\begin{array}{l}\text { Modest association between } \\
\text { transfusion of RBCs older than } 14 \text { days } \\
\text { and occurrence of new infections }\end{array}$ \\
\hline Dunn et al. [52] & 2012 & $2000-2010$ & $\begin{array}{l}\text { Retrospective } \\
\text { single-center }\end{array}$ & USA & NR & $\begin{array}{l}\text { Liver } \\
\text { transplant }\end{array}$ & 509 & $\begin{array}{c}\text { No independent association between } \\
\text { the age of RBCs and postoperative } \\
\text { infections }\end{array}$ \\
\hline \multicolumn{9}{|c|}{ Studies addressing organ failure } \\
\hline Zallen et al. [68] & 1999 & NR & $\begin{array}{l}\text { Retrospective } \\
\text { single-center }\end{array}$ & USA & NR & Trauma & 63 & $\begin{array}{l}\text { Mean age of blood (or number of } \\
\text { units older than } 14 \text { or } 21 \text { days) as } \\
\text { independent risk factors for MOF }\end{array}$ \\
\hline $\begin{array}{c}\text { Vamvakas et al. } \\
{[56]}\end{array}$ & 2000 & 1995 & $\begin{array}{l}\text { Retrospective } \\
\text { single-center }\end{array}$ & USA & $\begin{array}{c}\text { Mix } \\
\text { (mostly } \\
\text { not) }\end{array}$ & $\begin{array}{l}\text { Cardiac } \\
\text { surgery }\end{array}$ & 268 & $\begin{array}{l}\text { Length of RBC storage not associated } \\
\text { with prolonged endotracheal } \\
\text { intubation }\end{array}$ \\
\hline Keller et al. [58] & 2002 & 1998-1999 & $\begin{array}{l}\text { Retrospective } \\
\text { single-center }\end{array}$ & USA & No & Trauma & 86 & $\begin{array}{c}\text { Duration of MV not associated with } \\
\text { RBC storage duration }\end{array}$ \\
\hline $\begin{array}{l}\text { Leal-Noval et al. } \\
{[55]}\end{array}$ & 2003 & $1998-2000$ & $\begin{array}{l}\text { Prospective } \\
\text { single-center }\end{array}$ & Europe & No & $\begin{array}{l}\text { Cardiac } \\
\text { surgery }\end{array}$ & 585 & $\begin{array}{l}\text { No relationship between } \mathrm{RBC} \text { storage } \\
\text { duration and prolonged MV }\end{array}$ \\
\hline Gajic et al. [70] & 2004 & 2001 & $\begin{array}{l}\text { Retrospective } \\
\text { single-center }\end{array}$ & USA & Mix & ICU & 181 & $\begin{array}{c}\text { No association between mean age or } \\
\text { age of the oldest unit transfused and } \\
\text { occurrence of ALI }\end{array}$ \\
\hline Yap et al. [41] & 2008 & 2001-2007 & $\begin{array}{l}\text { Retrospective } \\
\text { single-center }\end{array}$ & Australia & $\begin{array}{l}\text { Mix }(3.8 \% \\
\quad \text { LR) }\end{array}$ & $\begin{array}{l}\text { Cardiac } \\
\text { surgery }\end{array}$ & 670 & $\begin{array}{l}\text { No association between storage } \\
\text { duration and occurrence of } \\
\text { postoperative renal failure or } \\
\text { prolonged MV }\end{array}$ \\
\hline Koch et al. [32] & 2008 & 1998-2006 & $\begin{array}{l}\text { Retrospective } \\
\text { single-center }\end{array}$ & USA & Mix & $\begin{array}{l}\text { Cardiac } \\
\text { surgery }\end{array}$ & 6,002 & $\begin{array}{l}\text { Increased risk of a composite outcome } \\
\text { (including MOF and renal failure) with } \\
\text { transfusion of older blood; higher } \\
\text { rates of } \mathrm{MV}>72 \text { hours when patients } \\
\text { transfused only old RBC }\end{array}$ \\
\hline $\begin{array}{c}\text { Weinberg et al. } \\
{[46]}\end{array}$ & 2008 & $2000-2007$ & $\begin{array}{l}\text { Retrospective } \\
\text { single-center }\end{array}$ & USA & Yes & Trauma & 430 & $\begin{array}{c}\text { Old blood (> } 14 \text { days) associated with } \\
\text { acute renal dysfunction after } \\
\text { adjustment }\end{array}$ \\
\hline $\begin{array}{l}\text { McKenny et al. } \\
\text { [39] }\end{array}$ & 2011 & $2002-2007$ & $\begin{array}{l}\text { Retrospective } \\
\text { single-center }\end{array}$ & Europe & Yes & $\begin{array}{l}\text { Cardiac } \\
\text { surgery }\end{array}$ & 1,153 & $\begin{array}{l}\text { No association between storage } \\
\text { duration and occurrence of } \\
\text { postoperative renal failure or } \\
\text { prolonged MV }\end{array}$ \\
\hline Sanders et al. [57] & 2011 & $2005-2007$ & $\begin{array}{l}\text { Retrospective } \\
\text { single-center }\end{array}$ & Europe & Yes & $\begin{array}{l}\text { Cardiac } \\
\text { surgery }\end{array}$ & 444 & $\begin{array}{l}\text { Higher rates of renal failure among } \\
\text { patients transfused with old blood }\end{array}$ \\
\hline Kor et al. [28] & 2012 & 2008-2010 & $\begin{array}{l}\text { Randomized } \\
\text { single-center } \\
\text { study }\end{array}$ & USA & Yes & $\mathrm{ICU}$ & 100 & $\begin{array}{l}\text { Similar measures of pulmonary } \\
\text { function after transfusion of either } \\
\text { fresh or standard issue RBCs }\end{array}$ \\
\hline
\end{tabular}


Table 2 Overview of the studies reporting the age of transfused red blood cells (RBCs) and patient outcomes. (Continued)

\begin{tabular}{|c|c|c|c|c|c|c|c|c|}
\hline $\begin{array}{l}\text { Weiskopf et al. } \\
\text { [69] }\end{array}$ & 2012 & NR & $\begin{array}{c}\text { Randomized } \\
\text { single-center } \\
\text { study }\end{array}$ & USA & Mix & Volunteers & 35 & $\begin{array}{l}\text { Equivalent mild decrements in } \\
\text { pulmonary gas exchange variables } \\
\text { after transfusion of either fresh ( } 1.7 \\
\text { hour) or older (> } 21 \text { days) RBCs }\end{array}$ \\
\hline \multicolumn{9}{|c|}{ Studies addressing tissue oxygenation and microcirculation } \\
\hline Marik et al. [71] & 1993 & NR & $\begin{array}{l}\text { Prospective } \\
\text { single-center } \\
\text { study }\end{array}$ & USA & NR & $\mathrm{ICU}$ & 23 & $\begin{array}{l}\text { Inverse correlation between the age } \\
\text { of transfused RBCs and the maximal } \\
\text { change in gastric mucosal pH (pHi) }\end{array}$ \\
\hline $\begin{array}{c}\text { Fernandes et al. } \\
{[72]}\end{array}$ & 2001 & 1996 & $\begin{array}{c}\text { Randomized } \\
\text { single-center } \\
\text { study }\end{array}$ & $\begin{array}{l}\text { South } \\
\text { America }\end{array}$ & NR & ICU septic & 15 & $\begin{array}{l}\text { No correlation between the age of } \\
\text { transfused RBCs and the } \mathrm{pHi}\end{array}$ \\
\hline Walsh et al. [73] & 2004 & $1999-2000$ & $\begin{array}{l}\text { Randomized } \\
\text { single-center } \\
\text { study }\end{array}$ & Europe & Yes & $\mathrm{ICU}$ & 22 & $\begin{array}{l}\text { No difference in } \mathrm{pHi} \text { or gastric to } \\
\text { arterial } \mathrm{PCO}_{2} \text { gap with transfusions of } \\
\text { fresh or older RBCs }\end{array}$ \\
\hline Sakr et al. [75] & 2007 & NR & $\begin{array}{l}\text { Prospective } \\
\text { single-center }\end{array}$ & Europe & Yes & ICU & 35 & $\begin{array}{c}\text { No correlation between the storage } \\
\text { time and the changes in capillary } \\
\text { perfusion }\end{array}$ \\
\hline $\begin{array}{l}\text { Leal-Noval et al. } \\
\qquad \text { [77] }\end{array}$ & 2008 & $2004-2006$ & $\begin{array}{l}\text { Prospective } \\
\text { single-center }\end{array}$ & Europe & Yes & Severe TBI & 66 & $\begin{array}{c}\text { Transfusion of RBCs aged more than } \\
19 \text { days failed to increase cerebral } \\
\text { tissue oxygenation }\end{array}$ \\
\hline Kiraly et al. [79] & 2009 & NR & $\begin{array}{l}\text { Prospective } \\
\text { single-center }\end{array}$ & USA & NR & Trauma & 32 & $\begin{array}{c}\text { Patients transfused with > } 21 \text { days old } \\
\text { RBCs had a significant decrease in the } \\
\text { area under the curve of tissue } \\
\text { saturation }\left(\mathrm{StO}_{2}\right)\end{array}$ \\
\hline Creteur et al. [81] & 2009 & NR & $\begin{array}{c}\text { Prospective } \\
\text { single-center }\end{array}$ & Europe & Yes & $\mathrm{ICU}$ & 44 & $\begin{array}{l}\text { No association between RBC storage } \\
\text { time and oxygenation variables (NIRS) }\end{array}$ \\
\hline Yuruk et al. [76] & 2012 & NR & $\begin{array}{c}\text { Randomized } \\
\text { single-center } \\
\text { study }\end{array}$ & Europe & Yes & $\begin{array}{l}\text { Hematology } \\
\text { patients }\end{array}$ & 20 & $\begin{array}{l}\text { Increase in perfused vessel density } \\
\text { similar in both RBC age groups }\end{array}$ \\
\hline Berra et al. [82] & 2012 & 2010 & $\begin{array}{l}\text { Randomized } \\
\text { single-center } \\
\text { study }\end{array}$ & USA & Yes & $\begin{array}{l}\text { Healthy } \\
\text { volunteers }\end{array}$ & 9 & $\begin{array}{l}\text { Reactive hyperemia index unchanged } \\
\text { after transfusion of } 40 \text {-day stored } \\
\text { blood compared with transfusion of } \\
\text { three-day stored blood }\end{array}$ \\
\hline $\begin{array}{c}\text { Roberson et al. } \\
\text { [83] }\end{array}$ & 2012 & NR & $\begin{array}{l}\text { Prospective } \\
\text { single-center }\end{array}$ & USA & Yes & $\begin{array}{l}\text { Healthy } \\
\text { volunteers }\end{array}$ & 8 & $\begin{array}{l}\text { No effect of storage duration on tissue } \\
\text { oxygen saturation and sublingual } \\
\text { microcirculatory flow index }\end{array}$ \\
\hline $\begin{array}{l}\text { Kopterides et al. } \\
\text { [84] }\end{array}$ & 2012 & 2008-2011 & $\begin{array}{l}\text { Prospective } \\
\text { single-center }\end{array}$ & Europe & Mix & ICU septic & 37 & $\begin{array}{l}\text { No relationship between age of RBCs } \\
\text { and change in lactate/pyruvate ratio } \\
\text { (microdialysis) }\end{array}$ \\
\hline \multicolumn{9}{|l|}{ Other outcomes } \\
\hline Wasser et al. [87] & 1989 & NR & $\begin{array}{c}\text { Randomized } \\
\text { single-center } \\
\text { study }\end{array}$ & Europe & No & $\begin{array}{l}\text { Cardiac } \\
\text { surgery }\end{array}$ & 237 & $\begin{array}{l}\text { No differences in postoperative } \\
\text { bleeding, coagulation tests, or } \\
\text { transfusion requirements }\end{array}$ \\
\hline Mynster et al. [53] & 2001 & 1991-1993 & $\begin{array}{l}\text { Retrospective } \\
\text { multicenter }\end{array}$ & Europe & No & Cancer & 740 & $\begin{array}{c}\text { Higher recurrence rate of cancer in } \\
\text { patients who received a transfusion of } \\
\text { RBCs stored }<21 \text { days }\end{array}$ \\
\hline $\begin{array}{l}\text { Leal-Noval et al. } \\
\qquad 55]\end{array}$ & 2003 & $1998-2000$ & $\begin{array}{l}\text { Prospective } \\
\text { single-center }\end{array}$ & Europe & No & $\begin{array}{l}\text { Cardiac } \\
\text { surgery }\end{array}$ & 585 & $\begin{array}{l}\text { No association between duration of } \\
\text { storage of RBCs and postoperative } \\
\text { myocardial infarction }\end{array}$ \\
\hline $\begin{array}{l}\text { Weiskopf et al. } \\
\text { [88] }\end{array}$ & 2006 & NR & $\begin{array}{c}\text { Randomized } \\
\text { single-center } \\
\text { study }\end{array}$ & USA & No & Volunteers & 9 & $\begin{array}{l}\text { Reversal of anemia-induced cognitive } \\
\text { dysfunction similar after transfusion of } \\
\text { fresh or stored RBCs }\end{array}$ \\
\hline Spinella et al. [47] & 2009 & $2004-2007$ & $\begin{array}{l}\text { Retrospective } \\
\text { single-center }\end{array}$ & USA & Mix & Trauma & 202 & $\begin{array}{c}\text { Association between maximum age of } \\
\text { RBCs ( }>21 \text { or } 28 \text { days) and deep vein } \\
\text { thrombosis (DVT) }\end{array}$ \\
\hline Naidech et al. [86] & 2011 & NR & $\begin{array}{l}\text { Retrospective } \\
\text { single-center }\end{array}$ & USA & NR & $\mathrm{SAH}$ & 119 & $\begin{array}{l}\text { No association between age of RBCs } \\
\text { and vasospasm or cerebral infarction }\end{array}$ \\
\hline
\end{tabular}


Table 2 Overview of the studies reporting the age of transfused red blood cells (RBCs) and patient outcomes. (Continued)

\begin{tabular}{cccccccc}
\hline Katsios et al. [85] & 2011 & $2001-2002$ & $\begin{array}{c}\text { Prospective } \\
\text { single-center }\end{array}$ & Canada & No & $\begin{array}{c}261 \\
\text { No association between the age of } \\
\text { transfused RBCs and the occurrence of } \\
\text { DVT }\end{array}$ \\
\hline Cata et al. [89] & 2011 & $1998-2007$ & $\begin{array}{c}\text { Retrospective } \\
\text { single-center }\end{array}$ & USA & NR & $\begin{array}{c}\text { Prostate } \\
\text { cancer }\end{array}$ & $\begin{array}{c}\text { No association between the age of } \\
\text { transfused RBCs and the five-year } \\
\text { prostate cancer recurrence }\end{array}$
\end{tabular}

DVT, deep vein thrombosis; HSCT, hematopoietic stem cell transplantation; ICU, intensive care unit; LOS, length of stay; LR, leukoreduced; MV, mechanical ventilation; NIRS, near-infrared spectroscopy; NR, not reported; $\mathrm{PCl}$, percutaneous coronary intervention; SAH, subarachnoid hemorrhage: TBI, traumatic brain injury.

Table 3 Randomized controlled trials assessing the effects of red blood cell (RBC) storage duration on various outcomes (feasibility trials excluded).

\begin{tabular}{|c|c|c|c|c|c|c|c|c|c|}
\hline $\begin{array}{c}\text { First } \\
\text { author }\end{array}$ & $\begin{array}{c}\text { Year } \\
\text { published } \\
\text { (recruitment } \\
\text { period) }\end{array}$ & $\begin{array}{l}\text { Country/ } \\
\text { region }\end{array}$ & $\begin{array}{l}\text { Leuko- } \\
\text { reduction }\end{array}$ & Setting & $\begin{array}{l}\text { Number } \\
\text { of } \\
\text { patients }\end{array}$ & $\begin{array}{l}\text { Number of } \\
\text { units } \\
\text { transfused }\end{array}$ & $\begin{array}{l}\text { Age of } \\
\text { RBCs in } \\
\text { each } \\
\text { group }\end{array}$ & $\begin{array}{l}\text { Outcome(s) } \\
\text { reported }\end{array}$ & Summary of results \\
\hline $\begin{array}{l}\text { Wasser } \\
\text { et al. [87] }\end{array}$ & 1989 (NR) & Europe & No & $\begin{array}{l}\text { Cardiac } \\
\text { surgery }\end{array}$ & $\begin{array}{l}237 \text { (118 in } \\
\text { fresh } \\
\text { group, } 119 \\
\text { in old } \\
\text { group) }\end{array}$ & $\begin{array}{l}5.4+/-1.9 \\
\text { (fresh } \\
\text { group) and } \\
6.0+/-2.4 \\
\text { (older } \\
\text { group) }\end{array}$ & $\begin{array}{l}<12 \mathrm{~h} \\
\text { (fresh } \\
\text { group) vs. } \\
2-5 \text { days } \\
\text { (older } \\
\text { group) }\end{array}$ & $\begin{array}{l}\text { Postoperative } \\
\text { bleeding }\end{array}$ & $\begin{array}{l}\text { No differences in } \\
\text { postoperative bleeding, } \\
\text { coagulation tests, or } \\
\text { transfusion } \\
\text { requirements }\end{array}$ \\
\hline $\begin{array}{l}\text { Fernandes } \\
\text { et al. [72] }\end{array}$ & 2001 (1996) & $\begin{array}{l}\text { South } \\
\text { America }\end{array}$ & NR & $\begin{array}{l}\text { ICU septic } \\
\text { patients }\end{array}$ & $\begin{array}{c}15(10 \\
\text { transfused, } \\
5 \text { receiving } \\
5 \% \\
\text { albumin) }\end{array}$ & 1 unit & $\begin{array}{l}12.8 \pm 8.1 \\
\text { days in } \\
\text { transfused } \\
\text { group }\end{array}$ & $\begin{array}{l}\text { Oxygen delivery } \\
\text { and } \\
\text { consumption; } \\
\text { changes in pHi } \\
\text { (tonometry) }\end{array}$ & $\begin{array}{c}\text { No correlation between } \\
\text { the age of transfused } \\
\text { RBCs and the pHi }\end{array}$ \\
\hline $\begin{array}{l}\text { Walsh } \\
\text { et al. [73] }\end{array}$ & $\begin{array}{l}2004 \text { (1999- } \\
2000)\end{array}$ & Europe & Yes & $\begin{array}{l}\text { ICU patients } \\
\text { with MV }\end{array}$ & $\begin{array}{l}22 \text { (10 in } \\
\text { fresh } \\
\text { group, } 22 \\
\text { in old } \\
\text { group) }\end{array}$ & 2 units & $\begin{array}{l}2 \text { days vs. } \\
28 \text { days } \\
\text { (median } \\
\text { durations) }\end{array}$ & $\begin{array}{l}\text { pHi or gastric to } \\
\text { arterial } \mathrm{PCO}_{2} \\
\text { gap }\end{array}$ & $\begin{array}{c}\text { No difference in } \mathrm{pHi} \text { or } \\
\text { gastric to arterial } \mathrm{PCO}_{2} \\
\text { gap between fresh or } \\
\text { older RBCs }\end{array}$ \\
\hline $\begin{array}{l}\text { Weiskopf } \\
\text { et al. [88] }\end{array}$ & 2006 (NR) & USA & No & $\begin{array}{l}\text { Healthy } \\
\text { volunteers }\end{array}$ & $\begin{array}{c}9 \\
\text { (crossover } \\
\text { design) }\end{array}$ & $\begin{array}{c}2 \\
\text { autologous } \\
\text { units }\end{array}$ & $\begin{array}{l}3.4 \text { hours } \\
\text { vs. } 23 \text { days } \\
\text { (median } \\
\text { durations) }\end{array}$ & $\begin{array}{l}\text { Cognitive } \\
\text { dysfunction }\end{array}$ & $\begin{array}{l}\text { Reversal of anemia- } \\
\text { induced cognitive } \\
\text { dysfunction similar after } \\
\text { transfusion of fresh or } \\
\text { stored RBCs }\end{array}$ \\
\hline $\begin{array}{c}\text { Berra et al. } \\
\text { [82] }\end{array}$ & $2012(2010)$ & USA & Yes & $\begin{array}{l}\text { Healthy } \\
\text { volunteers }\end{array}$ & $\begin{array}{c}9 \\
\text { (crossover } \\
\text { design) }\end{array}$ & $\begin{array}{c}1 \\
\text { autologous } \\
\text { unit }\end{array}$ & $\begin{array}{l}3 \text { days vs. } \\
40 \text { days }\end{array}$ & $\begin{array}{l}\text { Reactive } \\
\text { hyperhemia } \\
\text { index }\end{array}$ & $\begin{array}{l}\text { Reactive hyperemia } \\
\text { index unchanged after } \\
\text { transfusion of } 40 \text {-day } \\
\text { stored blood compared } \\
\text { with transfusion of } \\
\text { three-day stored blood }\end{array}$ \\
\hline $\begin{array}{l}\text { Yuruk } \\
\text { et al. [76] }\end{array}$ & 2012 (NR) & Europe & Yes & $\begin{array}{l}\text { Hematology } \\
\text { patients }\end{array}$ & $\begin{array}{c}20 \text { (10 per } \\
\text { arm) }\end{array}$ & 3 units & $\begin{array}{l}7 \text { days vs. } \\
23 \text { days } \\
\text { (median } \\
\text { durations) }\end{array}$ & $\begin{array}{c}\text { Sublingual } \\
\text { microcirculation } \\
\text { variables }\end{array}$ & $\begin{array}{l}\text { Increase in perfused } \\
\text { vessel density similar in } \\
\text { both RBC age groups }\end{array}$ \\
\hline $\begin{array}{l}\text { Weiskopf } \\
\text { et al. [69] }\end{array}$ & 2012 (NR) & USA & $\begin{array}{l}\text { Mix (57\% } \\
\text { LR) }\end{array}$ & $\begin{array}{c}\text { Healthy } \\
\text { volunteers }\end{array}$ & $\begin{array}{c}35 \\
\text { (crossover } \\
\text { design) }\end{array}$ & $\begin{array}{c}2 \\
\text { autologous } \\
\text { units }\end{array}$ & $\begin{array}{l}1.7 \text { hours } \\
\text { vs. } 24.5 \\
\text { days }\end{array}$ & $\begin{array}{c}\text { Pulmonary } \\
\text { function tests } \\
\left.\left(\text { A-aDO2, } V_{D} N_{T}\right)\right)\end{array}$ & $\begin{array}{l}\text { Equivalent mild } \\
\text { decrements in } \\
\text { pulmonary gas } \\
\text { exchange variables after } \\
\text { transfusion of either } \\
\text { fresh or older RBCs }\end{array}$ \\
\hline $\begin{array}{c}\text { Kor et al. } \\
\text { [28] }\end{array}$ & $\begin{array}{l}2012(2008- \\
2010)\end{array}$ & USA & Yes & $\begin{array}{l}\text { ICU patients } \\
\text { with MV }\end{array}$ & $\begin{array}{l}100(50 \\
\text { per arm) }\end{array}$ & $\begin{array}{l}1 \text { unit in } \\
\text { each group }\end{array}$ & $\begin{array}{l}4 \text { days vs. } \\
26.5 \text { days } \\
\text { (median } \\
\text { durations) }\end{array}$ & $\begin{array}{l}\text { Pulmonary } \\
\text { function tests; } \\
\text { mortality (not } \\
\text { powered for } \\
\text { this) }\end{array}$ & $\begin{array}{c}\text { Similar measures of } \\
\text { pulmonary function } \\
\text { (and mortality) after } \\
\text { transfusion of either } \\
\text { fresh or standard issue } \\
\text { RBCs }\end{array}$ \\
\hline
\end{tabular}


transfused and mortality, even though the authors used universal leukoreduction [44]. The same authors reported similar data in another retrospective study with a somewhat higher mortality rate with older blood when patients received more than three RBC units $(20.1 \%$ in fresh blood vs. $27.0 \%$ in the old blood group, $P=0.08$ ) [45]. In less severely injured trauma patients (mean ISS 14.4), transfusion of older blood (> 14 days old) was also associated with increased mortality, although to a lesser extent (OR: 1.12, CI: 1.02 to 1.23) [46]. In a smaller retrospective analysis of 202 patients transfused with at least five units of RBCs, Spinella et al. [47] found that hospital mortality was higher for patients transfused with older RBCs (maximum RBC age: 28 or more days) than with younger RBCs (maximum $\mathrm{RBC}$ age less than 28 days) $(26.7 \%$ vs. $13.9 \%, P=0.02)$. In a multivariate analysis, increased storage time was independently associated with mortality (OR: 4.00; 95\% CI: 1.31 to 11.61). Not all studies in trauma patients have reported deleterious effects of RBC storage on mortality. In a retrospective study of 271 trauma patients, Murrell et al. [48] found no correlation between the age of blood (expressed as the 'dose of aged blood') and hospital mortality (OR: 1.21 , 95\% CI: 0.87 to 1.69$)$ after controlling for confounders. In another retrospective cohort of 820 transfused trauma patients, the total number of RBC units but not the number of older ( $>14$ days old) units transfused was independently associated with increased mortality [49]. These studies were, however, smaller than the previous ones.

Two studies examined the outcomes of medical patients with cardiovascular disease. In a retrospective study of 4,933 patients, Eikelboom et al. [50] showed a greater risk of hospital mortality (relative risk 1.48, 95\% CI: 1.07 to 2.05 ) in the highest age quartile of RBCs ( 31 to 42 days). In a retrospective cohort study of 909 transfused patients following percutaneous coronary intervention, RBC storage duration was associated with 30-day mortality (HR: 1.02 (1.01 to 1.04 ), $P=0.02$ ). Patients receiving only RBCs aged $>28$ days had an even higher risk of mortality (HR: 2.49 (1.45 to 4.25), $P=0.001$ ) [51]. In a retrospective analysis of 509 patients undergoing liver transplantation, transfusion of more than 10 units of RBCs was associated with increased two-year mortality, but the age of the transfused RBCs was not [52]. In a secondary analysis of a prospective multicenter study on patients with colorectal cancer [53], transfused patients had a shorter survival than the non-transfused patients (3.0 years vs. 4.6 years, $P=$ 0.004 ) but mortality was not significantly different between patients transfused with RBCs aged more or less than 21 days. In a retrospective single-center study on 555 patients undergoing hematopoietic stem cell transplantation, nonrelapse 100-day mortality was reduced in the subgroup of patients receiving exclusively old blood ( $>14$ days old) compared to those receiving fresher $(<14$ days old) blood (6\% vs. $0 \%$ at 100 days, $P=0.04$ ) [54].

\section{Influence on hospital or ICU length of stay}

Nine studies evaluated the LOS as a surrogate marker of global morbidity associated with RBC transfusion. Six of the studies included cardiac surgery patients; when controlling for potential confounders, there was no relationship between age of transfused RBCs and postoperative LOS in five of the studies $[38,39,41,55,56]$. In the only prospective study, there was a significant association between ICU LOS and number of units transfused but not the mean duration of RBC storage [55]. Other retrospective studies yielded similar results. In the study of van De Watering et al. mentioned earlier [38], storage time had no independent effect on ICU LOS. In the studies by Yap et al. [41] and McKenny et al. [39], there was no association between length of storage and ICU LOS. In another retrospective study of 268 patients undergoing CABG, Vamvakas and Carven could not find any association between $\mathrm{RBC}$ storage duration and postoperative ICU and hospital LOS in a multivariate analyses also controlling for number of units received [56]. One retrospective study of 444 cardiac surgery patients by Sanders et al. [57] yielded different results, with the age of blood a significant but modest predictor of postoperative LOS (OR: 1.05, 95\% CI: 1.01 to 1.09 ). However, this analysis was limited by a number of imbalances between groups.

Two studies evaluated LOS in trauma patients. In a small retrospective study of 86 transfused patients, the number of units of blood older than 14 days was strongly associated with an increased hospital LOS [58], each additional unit older than 14 days old being associated with an increased length of stay of two days. In the study by Murrell and coworkers mentioned earlier, the dose of aged blood was significantly associated with a longer ICU stay (RR 1.15, 95\% CI: 1.11 to 1.20) after controlling for confounders [48].

In the study by Kekre and coworkers on patients undergoing hematopoietic stem cell transplantation [54], there was no correlation between age of transfused RBCs and hospital LOS.

\section{Influence on infections}

Eighteen studies reported on the possible influence of age of transfused RBCs on the risk of infection.

Studies performed in cardiac surgery patients generated conflicting results. In the prospective study of Leal-Noval and coworkers [55], there was an independent relation between the oldest RBC unit transfused (but not the mean duration of storage of all the transfused units) and the development of postoperative pneumonia (OR: 1.06, 95\% CI: 1.01 to $1.11, P=0.018$ ), but not mediastinitis. In the retrospective study by Koch and coworkers [32], 
patients transfused with older RBCs ( $>14$ days old) had significantly higher rates of postoperative sepsis or septicemia ( $4.0 \%$ vs. $2.8 \%, P=0.01)$, whereas rates of pneumonia and wound infections were similar. Two other studies reported detrimental effects associated with storage time of non-leukoreduced RBCs. In a retrospective, single center study of 256 cardiac surgery patients, Vamvakas et al. [59] reported an independent relationship between the age of transfused RBCs and the incidence of postoperative pneumonia or wound infection after correcting for the number of units transfused. In this study, the risk of pneumonia increased by $1 \%$ per day of increase in the mean storage time of transfused red cells $(P<0.05)$. In a multicenter retrospective Danish study on 1,748 patients transfused after CABG, storage time more than 14 days was associated with a greater risk of postoperative wound infections and septicemia (adjusted OR: 2.5, 95\% CI: 1.2 to 4.2 ). The adjusted risk of severe infection increased by $23 \%$ for each unit transfused in patients receiving only old RBCs [60]. Other studies found no link between storage time of transfused RBCs and infections. In the smaller cohort of Yap and coworkers [41], no association was found between storage of RBCs and postoperative pneumonia in multivariate analyses. Similar findings were reported in the study by McKenny and coworkers [39].

Two studies were conducted in patients undergoing surgery for colorectal cancer. In a single-center, retrospective study performed between 1980 and 1992 on 290 patients undergoing colorectal resection for adenocarcinoma, age of transfused RBCs was not different in subjects developing postoperative infections and those who did not [61]. In a retrospective analysis of 225 patients undergoing colorectal cancer surgery, Mynster and Nielsen [62] found that a blood storage time exceeding 20 days was an independent risk factor for postoperative infection (wound or intra-abdominal infection, anastomotic leakage, pneumonia, septicemia; OR, 2.35; 95\% CI, 1.27 to 4.37 ; $P=0.007$ ).

Five studies were conducted in trauma patients, all suggesting deleterious consequences of storage duration on infectious complications. In the study by Weinberg and coworkers [46] evaluating 1,624 trauma patients, occurrence of pneumonia was directly related to the volume of old blood ( $>14$ days old) transfused (OR 1.10 , CI 1.04 to 1.17 ), but not young blood (< 14 days old), after multiple adjustments. Also, in a retrospective cohort of 1,183 transfused trauma patients, receipt of exclusively old RBCs (>14 days) significantly increased the risk of pneumonia (adjusted RR for age, gender, ISS, mechanism of injury, ventilator days and RBC volume 1.42 (1.01 to 2.02)), whereas the transfusion of exclusively young RBCs (<14 days) or mixed RBCs did not [63]. In a smaller study of 61 massively transfused trauma patients, those who developed major infections had received more units of RBCs greater than 14 or 21 days old. The number of units older than 14 and 21 days was identified as an independent risk factor for major infections in a multivariate analysis [64]. In the previously described study by Hassan and coworkers [49], the number of older ( $>14$ days old) units of RBCs transfused was a significant risk factor for severe sepsis or septic shock especially when more than seven units were transfused (OR 1.9, 95\% CI: 1.1 to $3.4, P=0.03$ ). Recently, in a retrospective study of 196 transfused trauma patients receiving selective digestive tract decontamination, Juffermans et al. found a modest association between transfusion of RBCs older than 14 days and occurrence of new infections in multivariate analysis (OR 1.04, 95\% CI 1.01 to 1.07) [65].

We identified three studies in septic and/or ICU patients. In a prospective study of 449 medical and surgical ICU patients, Taylor and colleagues [66] found that the number of units of transfused RBCs was associated with an increased risk of nosocomial infection in a multivariate regression analysis, but the maximum age of transfused RBCs was not. In a retrospective study of 134 patients with sepsis, Juffermans et al. [67] found a direct relation between the total number of transfused $\mathrm{RBCs}$ and the risk of developing secondary infections (OR 1.26, 95\% CI 1.09 to 1.45 ) after controlling for immunosuppression. Storage time was identified as a confounder for the association of RBCs with infection. In another retrospective, single-center study of 534 general ICU patients, Dessertaine et al. [43] found no independent association between the age of transfused red cells (median of the maximum RBC ages: 23 days) and the development of nosocomial infection.

The risk of infection was also studied in other populations. In a retrospective analysis of 509 patients undergoing liver transplantation, Dunn et al. [52] reported no independent association between the age of transfused $\mathrm{RBCs}$ and the incidence of postoperative infections. In a secondary analysis of an RCT on patients undergoing knee arthroplasty, there was no independent association between postoperative wound infection and age of transfused RBCs [68].

\section{Influence on organ failure (including acute kidney injury and respiratory failure)}

We identified 12 studies that addressed the effects of transfused RBCs on multiple organ failure (MOF).

Four studies looked at postoperative acute renal failure in cardiac surgery patients. A retrospective study by Koch and coworkers [32] found an increased risk of MOF (unadjusted comparison $0.7 \%$ vs. $0.2 \%, P=0.007$ ) and renal insufficiency (unadjusted comparison $2.7 \%$ vs. $1.6 \%, P=0.003$ ) associated with transfusion of older blood (> 14 days old). In a multivariate analysis, there 
was an increased risk of a composite outcome (including MOF and renal failure) associated with transfusion of older blood (adjusted OR: 1.16; 95\% CI: 1.01 to 1.33, $P=0.03)$. A smaller study by Sanders and coworkers [57] also showed somewhat higher rates of renal failure among patients transfused with any old blood $(12.5 \%$ vs. $3.1 \%, P=0.054$ ) (unadjusted risks) compared to other patients. In a multivariate analysis, every day increase in storage was associated with a $7 \%$ increase in risk of new renal complications. These results have been challenged by two other studies that found no association between storage duration and occurrence of postoperative renal failure $[39,41]$.

Two studies included trauma patients. In a small study of 63 matched case-control trauma patients, Zallen and coworkers found that mean age of blood and number of units older than 14 or 21 days were independent risk factors for MOF in a limited multivariate analysis [68]. In a study by Weinberg et al. [45] the receipt of old blood ( $>14$ days old) was associated with acute renal dysfunction (OR 1.18, CI 1.07 to 1.29) after adjustment for age, sex, ISS, thoracic injury and need for mechanical ventilation, whereas the receipt of young blood $(<14$ days old) was not.

Some studies focused on the development of respiratory failure, assessed by physiologic and immunologic variables, or the duration of mechanical ventilation $(\mathrm{MV})$. In a randomized, crossover study of 35 healthy volunteers, Weiskopf and coworkers [69] found equivalent mild decrements in pulmonary gas exchange (alveolo-arterial oxygen gradient $\left((\mathrm{A}-\mathrm{a}) \mathrm{DO}_{2}\right)$, dead space to tidal volume ratio $\left.\left(\mathrm{V}_{\mathrm{D}} / \mathrm{V}_{\mathrm{T}}\right)\right)$ after isovolemic transfusion of either two units of fresh (1.7 hour) or older (> 21 days) autologous RBCs. No differences between leukoreduced and non-leukoreduced units were noted. Also, in a single-center randomized clinical trial in mechanically ventilated ICU patients, patients randomized to receive exclusively fresh RBCs $(n=50$ patients, median RBC age: 4.0 days) had similar measures of pulmonary function (changes in $\mathrm{PaO}_{2} / \mathrm{FIO}_{2}$ ratio, changes in $\mathrm{V}_{\mathrm{D}} / \mathrm{V}_{\mathrm{T}}$, static compliance) when compared to those receiving standard issue $\mathrm{RBCs}(n=50$ patients, median RBC age: 26.5 days) [28]. Eight other observational studies analyzed the duration of MV or the occurrence of ALI. In the study by Koch and coworkers [32] in 6,002 cardiac surgery patients, patients receiving only old RBCs (14 days) had higher rates of MV $>72$ hours compared to those transfused with only younger $(<14$ days $)$ blood (unadjusted risk $9.7 \%$ vs. $5.6 \%, P<0.001$ ) but no adjusted risk for longer MV duration was calculated. These findings were not found in six other studies $[39,41,46,55,56,58]$. In a retrospective study on 181 mechanically ventilated ICU patients, Gajic and coworkers [70] found no association between storage variables (mean age or age of the oldest unit transfused) and occurrence of ALI.

\section{Influence on tissue oxygenation and the microcirculation}

Several studies using various devices addressed the question of whether aged RBCs could alter the microcirculation in humans. In a prospective, non-randomized study of 23 septic patients, Marik and Sibbald [71] reported an inverse correlation between the age of transfused RBCs (three units of stored RBCs of varying age) and the maximal change in gastric mucosal $\mathrm{pH}(\mathrm{pHi})$ during the subsequent hours $(\mathrm{r}=-0.71, P<0.001)$. In a multivariate analysis, age of transfused RBCs was the only predictor of the changes in $\mathrm{pHi}$, suggesting that older, less deformable RBCs could promote mucosal ischemia. These data were, however, challenged by later studies. In particular, Fernandes and colleagues [72] compared 15 anemic septic patients randomly assigned to receive either one RBC unit (mean storage time: $12.8 \pm 8.1$ days) or $500 \mathrm{~mL}$ of a $5 \%$ albumin solution. There was no increase in oxygen delivery or consumption following RBC transfusion (but the baseline hemoglobin concentration was relatively high) and no correlation between the age of transfused RBCs and the pHi. Likewise, in a randomized, double-blinded study on 22 anemic ICU patients, Walsh and coworkers [73] reported no difference in pHi or gastric to arterial $\mathrm{PCO}_{2}$ gap with transfusions of two units of leukoreduced RBCs stored for less than five days (median: 2 days) or more than 20 days (median: 28 days). Comparisons of this work with the previous study by Marik and Sibbald [71] is difficult because of differences in patient populations and the use or not of leukodepleted blood [74]. Sakr and coworkers [75] performed a prospective study evaluating transfusion-induced changes in the sublingual microcirculation of 35 septic patients (using an orthogonal polarization spectral imaging technique). Oxygen uptake and microcirculatory variables were globally unaltered after the administration of one or two units of leukoreduced RBCs (median age: 24 days; IQR: 12 to 28 days); considerable interindividual variability in sublingual capillary perfusion was noted among these patients and no correlation between the storage time and the changes in capillary perfusion was found [75].

In another small randomized trial on 20 hematology outpatients transfused with three units of either young (median: 7 days) or older blood (median: 23 days), viscosity and perfused vessel density in sublingual microcirculation (assessed with sidestream dark field imaging - SDF) increased after transfusion, but this increase was similar in both $\mathrm{RBC}$ age groups [76]. Interestingly, the aggregability index was also increased following $\mathrm{RBC}$ transfusion whereas the RBC deformability index was unchanged, with no differences between older and younger blood groups. 
Leal-Noval and coworkers [77] assessed the effects of transfusion of leukoreduced RBCs on cerebral tissue oxygenation $\left(\mathrm{PtiO}_{2}\right)$ in patients with severe traumatic brain injury divided into four quartiles according to length of storage of transfused RBCs (< 10 days, $n=18 ; 10$ to 14 days, $n=15 ; 15$ to 19 days, $n=17$; $>19$ days, $n=16$ ). Transfusion of RBCs stored for less than 19 days increased $\mathrm{PtiO}_{2}$ for up to six hours, whereas transfusion of RBCs aged more than 19 days failed to do so. There was a trend toward an inverse relationship between storage time and the relative increment in $\mathrm{PtiO}_{2}$ from the baseline value, but there were concerns about methodological limitations in this study [78]. Kiraly and coworkers [79] performed a prospective, non-randomized study in 32 hemodynamically stable, non-septic, ICU trauma patients requiring a transfusion. Patients transfused with 'old' red cells $(>21$ days old, $n=17$ patients) had a significant decrease in the area under the curve (AUC) of tissue oxygen saturation $\left(\mathrm{StO}_{2}\right)$ as measured by near-infrared spectroscopy (NIRS [80]), whereas patients receiving 'new' red cells $(<21$ days, $n=15$ patients) and a control, non-transfused group had a stable $\mathrm{StO}_{2}$ AUC. Moreover, a slightly negative correlation between the age of the oldest unit transfused and the changes in oxygenation was noted $\left(\mathrm{r}^{2}=0.25\right)$. In a prospective study on 44 hemodynamically stable ICU patients also monitored with NIRS, Creteur and coworkers [81] found no association between RBC storage time (median: 18 days; IQR: 11 to 27 days) and oxygenation variables (changes in the $\mathrm{StO}_{2}$ upslope, changes in NIR oxygen consumption). Also, in a randomized crossover study in nine healthy volunteers, reactive hyperemia index (measured by peripheral arterial tonometry and reflecting NO bioavailability and endothelial function) was unchanged after transfusion of one unit of 40-day stored autologous blood compared with transfusion of three-day stored blood [82]. Another recent study on eight healthy volunteers receiving sequentially one unit of seven-day AS-3 stored and one unit of 42-day stored autologous blood found no effect of storage duration on oxygenation variables (tissue oxygen saturation - brain and thenar eminence, and sublingual microcirculatory flow index) [83]. Recently, Kopterides et al. [84] reported no relationship between age of transfused RBCs (median: 16 days) and post-transfusional change in lactate/pyruvate ratio (microdialysis assessment) in 37 ICU patients with sepsis.

\section{Other outcomes}

a) Thrombotic events

In a retrospective study of 202 trauma patients, Spinella and coworkers found an association between maximum age of transfused RBCs (> 21 or 28 days) and the occurrence of deep vein thrombosis (DVT) but no multivariate analysis was performed to confirm this observation [47].
Moreover, these results were challenged by a prospective study of 261 medico-surgical ICU patients in which there was no association between the age of transfused RBCs and the occurrence of DVT [85]. Leal-Noval and coworkers found no association between duration of storage of transfused RBCs and postoperative myocardial infarction [55].

\section{b) Vasospasm after subarachnoid hemorrhage}

In a retrospective, single-center study of 119 patients transfused after SAH, Naidech and coworkers could not find any association between age of RBCs and poor outcomes (vasospasm, cerebral infarction, dependence or mortality at three months) [86].

\section{c) Bleeding}

One may hypothesize that stored blood (especially in the absence of leukoreduction) could increase bleeding through an altered viability of platelets and a decrease in coagulation factors, such as factor VIII. In patients undergoing CABG surgery, Wasser and coworkers [87] found no differences in postoperative bleeding, coagulation tests, or transfusion requirements between the study group (two units of fresh blood followed by stored RBCs (aged from two to five days) if required) and the control group (stored blood only), except for a subgroup of patients with thrombocytopenia.

\section{d) Cognitive dysfunction}

In a randomized crossover study on healthy volunteers submitted to acute normovolemic hemodilution (target hemoglobin $5 \mathrm{~g} / \mathrm{dl}$ ), Weiskopf et al. [88] found that reversal of anemia-induced cognitive dysfunction was similar after transfusion of two units of fresh (storage less than five hours) or stored (three weeks storage) RBCs.

\section{e) Cancer recurrence}

Immunomodulation associated with RBC transfusion may influence cancer recurrence after surgery. In a retrospective study of 740 patients with colorectal cancer, Mynster and coworkers [53] found a higher recurrence rate of cancer in patients who received a transfusion of RBCs stored < 21 days (HR: $1.5 ; 95 \%$ CI: 1.04 to 2.18 , $P=0.03$ for colorectal cancer) than in patients who received blood stored $\geq 21$ days. Another retrospective study of 316 patients undergoing surgery for prostate cancer found no association between the age of transfused allogeneic RBCs and the five-year cancer recurrence defined by prostate specific antigen levels [89].

\section{Discussion}

It is interesting to note the quasi-exponential growth in the number of publications related to the impact of RBC storage since 1989 , with $50 \%$ of the studies published during or after 2009. We identified 55 studies that reported an association between RBC storage and 
outcomes in adult patients. Of these, 26 studies (47\%) suggested detrimental effects of RBC storage on any clinical endpoint, whereas the remainder (53\%) did not.

Comparison among studies is difficult because of the high degree of heterogeneity. First, studies included different patient populations (cardiac surgery, trauma, sepsis, cancer patients) with different baseline risks. Interestingly, 91\% of the studies on trauma patients showed a deleterious impact of older RBCs on any endpoint, whereas only $45 \%$ of studies in cardiac surgery patients and $36 \%$ of studies in ICU patients suggested such an association. It is intriguing to consider that trauma patients may be more sensitive to the age of transfused RBCs than other patients [90]. Second, studies also included different mortality and morbidity outcomes and the criteria for organ dysfunction varied. Third, the way in which the age of transfused RBCs was reported also varied (mean age of all RBCs transfused, maximum age of RBCs, mean of the two oldest units, proportion of RBCs older than a given number of days,...), each analysis having its own advantages and limitations. Studies that report the mean or median age of all units transfused assume that fresher units offset the deleterious effect of older blood but this may not be true. Dichotomization of RBC age below or above a given time based on more or less proven pathophysiological evidence may also be problematic $[18,91]$. Recently, in a simulation-based analysis of four RCTs (three currently ongoing) that used distinct categorization of RBC storage, the type of temporal pattern assumed for the RBC storage lesion (smooth or sharp sigmoid curve centered on 7, 21 or 35 days; linear relation) had a profound impact on the statistical power of the trials for various outcomes, such that it was below $80 \%$ in numerous cases [91]; in particular, none of the studies had sufficient power to detect harmful consequences of $\mathrm{RBC}$ storage lesions if they were assumed to occur during the last week of storage. One must take into account the fact that older units are more often transfused during massive transfusions, which are obviously associated with worse outcomes [18]. Fourth, the blood preparation, including leukoreduction and use of additive solutions, varied among the studies; these practices have evolved over time and place and may influence the results. We found only 17 studies (35\% of all studies) that reported use of exclusively leukoreduced RBCs, 10 studies (20\%) reporting use of exclusively non-leukoreduced units and 11 studies (22\%) reported use of a mix of leukoreduced and non-leukoreduced RBCs.

Most of the studies were retrospective with associated limitations. Control for potential confounders is particularly important. Problems with bias (recently reviewed and listed in [18]) are well illustrated by the phenomenon of confounding by indication, occurring when the indication for a treatment causes the outcome studied [92]. The most notable example of this effect concerns sicker patients who have a poorer prognosis and are also prone to receive more blood transfusions, leading, if no correction is applied, to the spurious association between number of blood transfusions and poorer outcomes. Another, more subtle problem is that patients who need multiple transfusions are, in general, more likely to receive some older blood $[38,92]$. Transfusion thresholds, which have evolved over time and may vary between centers, may also play a role because they may modify the global exposure of a patient population to blood transfusions. Also, temporality of the association between transfusion and outcome is not always clear. Statistical methods, like multivariate analyses, are required to correct for some biases (for example, correction for the total number of units transfused, which is one of the most important biases in the transfusion literature). In some studies, there was poor control for the number of transfused RBCs or imbalances in $A B O$ groups [32,93] and possibly other unknown biases. The small number of patients included in many studies may also be of concern: 'negativity' of small studies should not be interpreted as proof for absence of effect [18].

Unfortunately, performing a quantitative meta-analysis is complicated by the significant clinical heterogeneity between studies, even if tests for statistical heterogeneity are passed. Moreover, meta-analyses do not improve the quality of individual studies [94], a major concern in our systematic review, which identified numerous biased studies. For these reasons we chose not to perform a metaanalysis. Nevertheless, some have been attempted [20-22], resulting, not surprisingly, in conflicting results. The most recent meta-analysis by Wang and coworkers showed detrimental effects of RBC storage on mortality (pooled OR 1.16 ; $95 \% \mathrm{CI} 1.07$ to $1.24, P=0.0001$ ), pneumonia (pooled OR $1.17 ; 95 \%$ CI 1.08 to $1.27, P=0.0001$ ) and multiple organ dysfunction syndrome (pooled OR 2.26; 95\% CI 1.56 to $3.25, P<0.0001)$; in this study, 97 patients $(95 \% \mathrm{CI}$ 63 to 199) was cited as the number to treat with exclusively fresh blood to save one life [20]. Another metaanalysis by Vamvakas that included only studies reporting adjusted results for mortality, found that the age of blood was not associated with a higher risk of mortality [22].

Transfusion policies in some centers recommend use of fresh RBCs for special populations, such as fetuses (intrauterine transfusions) or neonates, although the evidence for this approach is poor [95]. If one could choose, one would prefer fresher blood, although storage for a few days at $4^{\circ} \mathrm{C}$ may be beneficial to reduce the risk of some cell-associated viruses and other pathogens that cannot survive for long in these conditions [95]. Moreover, the delivery of fresher blood may be associated with major organizational problems although some recent pilot trials suggest the feasibility of such an approach $[96,97]$. Some would argue that the best way to resolve 
this problematic issue with adequate control for known and unknown biases may be achieved by large RCTs. It is intriguing to note that among eight randomized trials already published (without pilot trials) $[28,69,72,73$, $76,82,87,88]$, none demonstrated detrimental effects of $\mathrm{RBC}$ storage duration on outcomes, although the studies were small and mostly reported physiological outcomes. Several large randomized studies are ongoing (notably ABLE [98] and RECESS [99]) and their investigators have had to face various obstacles. First, as the differences in clinically relevant outcomes (such as mortality) are (if present) expected to be low, large numbers of patients are required to detect these differences. Second, these trials must overcome logistic problems so that the blood banks can appropriately deliver exclusively young or older RBC units (compared to an a priori defined threshold), as illustrated in several studies [96,100-102]. Third, even if the duration of storage is still within acceptable limits, administration of exclusively older RBCs to patients may raise ethical concerns. Use of standard RBCs instead of exclusively old RBCs may overcome this issue (for example, in the ABLE study [98]).

Our study has several strengths and limitations. First, we considered clinically relevant outcomes, which we discussed separately and were the basis for the study classification. Studies reporting biological outcomes (hemolysis [103], survival of RBCs after transfusion [104], hematocrit response [105] or mitogenic activity of plasma after transfusion [106]), or evolution of clinical scores after RBC administration [107], were not considered. Pediatric studies were also not included, because newborns and children may represent a particular population with specific pathologies. Also, we did not consider feasibility studies (pilot trials before large RCTs) $[96,97,101]$, which were not primarily powered to assess the clinical relevancy of RBC storage duration. Finally, we chose to refrain from performing a quantitative meta-analysis because of the high number of biased studies, which could have led to erroneous conclusions.

In conclusion, our systematic review indicates that the influence of RBC age on various outcomes is equivocal. The quality of the evidence is currently too poor to make recommendations to change current transfusion practice. Our observations are reassuring, because major differences would have serious consequences for the organization of blood banks [108].

\section{Key messages}

- The duration of red blood cell (RBC) storage before transfusion may alter RBC function and, hence, potentially influence the incidence of complications or even mortality, but this is controversial.

- Fifty-five studies were identified that had reported the effects of age of transfused RBCs on mortality or morbidity in adult patients, but the marked heterogeneity among studies prevented a formal metaanalysis.

- Half of the studies showed no deleterious effects of aged compared to fresh blood on any endpoint.

- This systematic review found no definitive argument to support the superiority of fresh over older RBCs for transfusion.

\section{Abbreviations}

$\mathrm{A}-\mathrm{aDO}_{2}$ : alveolo-arterial oxygen gradient; ALI: acute lung injury; ARDS: acute respiratory distress syndrome; $A \cup C$ : area under the curve; CABG: coronary artery bypass grafting; Cl: confidence interval; DVT: deep vein thrombosis; HR: hazard ratio; ICU: intensive care unit; IQR: interquartile range; LOS: length of stay; MOF: multiple organ failure; MV: mechanical ventilation; NIRS: nearinfrared spectroscopy; OR: odds ratio; $\mathrm{pHi}$ : gastric mucosal $\mathrm{pH}_{;} \mathrm{PtiO}_{2}$ : cerebral tissue oxygenation; RBC: red blood cell; RCT: randomized controlled trial; RR: relative risk; SAH: subarachnoid hemorrhage; SD: standard deviation; SDF: sidestream dark field; $\mathrm{StO}_{2}$ : tissue oxygen saturation; $\mathrm{V}_{\mathrm{D}}$ : dead space; $\mathrm{V}_{\mathrm{T}}$ : tidal volume.

\section{Authors' contributions}

$\mathrm{CL}$ and $J \mathrm{LV}$ designed the study. CL performed the literature search and drafted the manuscript. JLV critically revised the text. Both authors read and approved the final manuscript.

\section{Competing interests}

The authors have no competing interests to declare in relation to this article

Received: 22 January 2013 Revised: 26 March 2013

Accepted: 5 April 2013 Published: 8 April 2013

\section{References}

1. Hess JR: Red cell changes during storage. Transfus Apher Sci 2010, 43:51-59.

2. Klein $H G$, Spahn DR, Carson JL: Red blood cell transfusion in clinical practice. Lancet 2007, 370:415-426.

3. Marik PE, Corwin HL: Efficacy of red blood cell transfusion in the critically ill: a systematic review of the literature. Crit Care Med 2008, 36:2667-2674.

4. Chin-Yee I, Arya N, d'Almeida MS: The red cell storage lesion and its implication for transfusion. Transfus Sci 1997, 18:447-458.

5. Hamasaki N, Yamamoto M: Red blood cell function and blood storage. Vox Sang 2000, 79:191-197.

6. Korgun DK, Bilmen S, Yesilkaya A: Alterations in the erythrocyte antioxidant system of blood stored in blood bags. Res Commun Mol Pathol Pharmacol 2001, 109:357-363.

7. Bosman GJ, Lasonder E, Luten M, Roerdinkholder-Stoelwinder B, Novotny VM, Bos H, De Grip WJ: The proteome of red cell membranes and vesicles during storage in blood bank conditions. Transfusion 2008, 48:827-835

8. Sweeney J, Kouttab N, Kurtis J: Stored red blood cell supernatant facilitates thrombin generation. Transfusion 2009, 49:1569-1579.

9. Chin-Yee IH, Gray-Statchuk L, Milkovich S, Ellis CG: Transfusion of stored red blood cells adhere in the rat microvasculature. Transfusion 2009, 49:2304-2310.

10. Bosman GJ, Lasonder E, Groenen-Dopp YA, Willekens FL, Werre JM, Novotny VM: Comparative proteomics of erythrocyte aging in vivo and in vitro. J Proteomics 2010, 73:396-402.

11. Donadee C, Raat NJ, Kanias T, Tejero J, Lee JS, Kelley EE, Zhao X, Liu C, Reynolds H, Azarov I, Frizzell S, Meyer EM, Donnenberg AD, Qu L, Triulzi D, Kim-Shapiro DB, Gladwin MT: Nitric oxide scavenging by red blood cell microparticles and cell-free hemoglobin as a mechanism for the red cell storage lesion. Circulation 2011, 124:465-476.

12. Hod EA, Spitalnik SL: Harmful effects of transfusion of older stored red blood cells: iron and inflammation. Transfusion 2011, 51:881-885.

13. Hod EA, Brittenham GM, Billote GB, Francis RO, Ginzburg YZ, Hendrickson JE, Jhang J, Schwartz J, Sharma S, Sheth S, Sireci AN, 
Stephens HL, Stotler BA, Wojczyk BS, Zimring JC, Spitalnik SL: Transfusion of human volunteers with older, stored red blood cells produces extravascular hemolysis and circulating non-transferrin-bound iron. Blood 2011, 118:6675-6682.

14. Silliman CC, Voelkel NF, Allard JD, Elzi DJ, Tuder RM, Johnson JL, Ambruso DR: Plasma and lipids from stored packed red blood cells cause acute lung injury in an animal model. J Clin Invest 1998, 101:1458-1467.

15. Raat NJ, Verhoeven AJ, Mik EG, Gouwerok CW, Verhaar R, Goedhart PT, de Korte $D$, Ince $C$ : The effect of storage time of human red cells on intestinal microcirculatory oxygenation in a rat isovolemic exchange model. Crit Care Med 2005, 33:39-45.

16. van Bommel J, de Korte D, Lind A, Siegemund M, Trouwborst A, Verhoeven AJ, Ince C, Henny CP: The effect of the transfusion of stored RBCs on intestinal microvascular oxygenation in the rat. Transfusion 2001, 41:1515-1523.

17. d'Almeida MS, Jagger J, Duggan M, White M, Ellis C, Chin-Yee IH: A comparison of biochemical and functional alterations of rat and human erythrocytes stored in CPDA-1 for 29 days: implications for animal models of transfusion. Transfus Med 2000, 10:291-303.

18. van de Watering L: Pitfalls in the current published observational literature on the effects of red blood cell storage. Transfusion 2011, 51:1847-1854.

19. Spinella PC, Sparrow RL, Hess JR, Norris PJ: Properties of stored red blood cells: understanding immune and vascular reactivity. Transfusion 2011 51:894-900.

20. Wang D, Sun J, Solomon SB, Klein HG, Natanson C: Transfusion of older stored blood and risk of death: a meta-analysis. Transfusion 2012, 52:1184-1195.

21. Vamvakas EC: Meta-analysis of clinical studies of the purported deleterious effects of "old" (versus "fresh") red blood cells: are we at equipoise? Transfusion 2010, 50:600-610.

22. Vamvakas EC: Purported deleterious effects of "old" versus "fresh" red blood cells: an updated meta-analysis. Transfusion 2011, 51:1122-1123.

23. Lelubre C, Vincent JL: Red blood cell transfusion in the critically ill patient. Ann Intensive Care 2011, 1:43.

24. Hess JR: An update on solutions for red cell storage. Vox Sang 2006, 91:13-19.

25. Moher D, Liberati A, Tetzlaff J, Altman DG: Preferred reporting items for systematic reviews and meta-analyses: the PRISMA statement. PLOS Med 2009, 6:e1000097.

26. Basran S, Frumento RJ, Cohen A, Lee S, Du Y, Nishanian E, Kaplan HS, Stafford-Smith M, Bennett-Guerrero E: The association between duration of storage of transfused red blood cells and morbidity and mortality after reoperative cardiac surgery. Anesth Analg 2006, 103:15-20.

27. Basran S, Frumento R, Cohen A, Lee S, Du Y, Nishanian E, Kaplan HS, Stafford-Smith M, Bennett-Guerrero E: Request for retraction. Anesth Analg 2009, 108:1991.

28. Kor DJ, Kashyap R, Weiskopf RB, Wilson GA, van Buskirk CM, Winters JL, Malinchoc M, Hubmayr RD, Gajic O: Fresh red blood cell transfusion and short-term pulmonary, immunologic, and coagulation status: a randomized clinical trial. Am J Respir Crit Care Med 2012, 185:842-850

29. Pettila V, Westbrook AJ, Nichol AD, Bailey MJ, Wood EM, Syres G, Phillips LE, Street A, French C, Murray L, Orford N, Santamaria JD, Bellomo R, Cooper DJ: Age of red blood cells and mortality in the critically ill. Crit Care 2011, 15:R116.

30. Edgren G, Kamper-Jorgensen M, Eloranta S, Rostgaard K, Custer B, Ullum H, Murphy EL, Busch MP, Reilly M, Melbye M, Hjalgrim H, Nyren O: Duration of red blood cell storage and survival of transfused patients. Transfusion 2010, 50:1185-1195.

31. Saager L, Turan A, Dalton JE, Figueroa PI, Sessler DI, Kurz A: Erythrocyte storage duration is not associated with increased mortality in noncardiac surgical patients: a retrospective analysis of 6,994 patients. Anesthesiology 2013, 118:51-58.

32. Koch CG, Li L, Sessler DI, Figueroa P, Hoeltge GA, Mihaljevic T, Blackstone EH: Duration of red-cell storage and complications after cardiac surgery. N Engl J Med 2008, 358:1229-1239.

33. Dzik W: Fresh blood for everyone? Balancing availability and quality of stored RBCs. Transfus Med 2008, 18:260-265.

34. Benjamin RJ, Dodd RY: Red-cell storage and complications of cardiac surgery. N Engl J Med 2008, 358:2840-2841.
35. Frenzel T, Sibrowski W, Westphal M: Red-cell storage and complications of cardiac surgery. N Engl J Med 2008, 358:2841-2842.

36. Zimrin $A B$, Hess JR: Current issues relating to the transfusion of stored red blood cells. Vox Sang 2009, 96:93-103.

37. Jy W, Ricci M, Shariatmadar S, Gomez-Marin O, Horstman LH, Ahn YS: Microparticles in stored red blood cells as potential mediators of transfusion complications. Transfusion 2011, 51:886-893.

38. van de Watering L, Lorinser J, Versteegh M, Westendord R, Brand A: Effects of storage time of red blood cell transfusions on the prognosis of coronary artery bypass graft patients. Transfusion 2006, 46:1712-1718.

39. Mckenny M, Ryan T, Tate H, Graham B, Young VK, Dowd N: Age of transfused blood is not associated with increased postoperative adverse outcome after cardiac surgery. Br J Anaesth 2011, 106:643-649.

40. van Straten AH, Soliman Hamad MA, van Zundert AA, Martens EJ, ter Woorst JF, de Wolf AM, Scharnhorst V: Effect of duration of red blood cell storage on early and late mortality after coronary artery bypass grafting. J Thorac Cardiovasc Surg 2011, 141:231-237.

41. Yap CH, Lau L, Krishnaswamy M, Gaskell M, Yii M: Age of transfused red cells and early outcomes after cardiac surgery. Ann Thorac Surg 2008, 86:554-559.

42. Purdy FR, Tweeddale MG, Merrick PM: Association of mortality with age of blood transfused in septic ICU patients. Can J Anaesth 1997, 44:1256-1261.

43. Dessertaine G, Hammer L, Chenais F, Remy J, Schwebel C, Tabah A, AraSomohano C, Bonadona A, Hamidfar-Roy R, Barnoud D, Timsit JF: [Does red blood cell storage time still influence ICU survival?]. Transfus Clin Biol 2008, 15:154-159.

44. Weinberg JA, McGwin G Jr, Griffin RL, Huynh VQ, Cherry SA, Marques MB, Reiff DA, Kerby JD, Rue LW: Age of transfused blood: an independent predictor of mortality despite universal leukoreduction. J Trauma 2008, 65:279-282.

45. Weinberg JA, McGwin G Jr, Vandromme MJ, Marques MB, Melton SM Reiff DA, Kerby JD, Rue LW: Duration of red cell storage influences mortality after trauma. J Trauma 2010, 69:1427-1431.

46. Weinberg JA, McGwin G Jr, Marques MB, Cherry SA, Reiff DA, Kerby JD, Rue LW: Transfusions in the less severely injured: does age of transfused blood affect outcomes? J Trauma 2008, 65:794-798.

47. Spinella PC, Carroll CL, Staff I, Gross R, McQuay J, Keibel L, Wade CE, Holcomb JB: Duration of red blood cell storage is associated with increased incidence of deep vein thrombosis and in hospital mortality in patients with traumatic injuries. Crit Care 2009, 13:R151.

48. Murrell Z, Haukoos JS, Putnam B, Klein SR: The effect of older blood on mortality, need for ICU care, and the length of ICU stay after major trauma. Am Surg 2005, 71:781-785.

49. Hassan M, Pham TN, Cuschieri J, Warner K, Nester T, Maier RV, Shalhub S, O'Keefe GE: The association between the transfusion of older blood and outcomes after trauma. Shock 2011, 35:3-8.

50. Eikelboom JW, Cook RJ, Liu Y, Heddle NM: Duration of red cell storage before transfusion and in-hospital mortality. Am Heart J 2010, 159:737-743.

51. Robinson SD, Janssen C, Fretz EB, Berry B, Chase AJ, Siega AD, Carere RG, Fung A, Simkus G, Klinke WP, Hilton JD: Red blood cell storage duration and mortality in patients undergoing percutaneous coronary intervention. Am Heart J 2010, 159:876-881.

52. Dunn LK, Thiele RH, Ma JZ, Sawyer RG, Nemergut EC: Duration of red blood cell storage and outcomes following orthotopic liver transplantation. Liver Transp/ 2012, 18:475-481.

53. Mynster T, Nielsen HJ: Storage time of transfused blood and disease recurrence after colorectal cancer surgery. Dis Colon Rectum 2001, 44:955-964.

54. Kekre N, Chou A, Tokessey M, Doucette S, Tinmouth A, Tay J, Allan DS: Storage time of transfused red blood cells and impact on clinical outcomes in hematopoietic stem cell transplantation. Transfusion 2011, 51:2488-2494.

55. Leal-Noval SR, Jara-Lopez I, Garcia-Garmendia JL, Marin-Niebla A, HerruzoAviles A, Camacho-Larana P, Loscertales J: Influence of erythrocyte concentrate storage time on postsurgical morbidity in cardiac surgery patients. Anesthesiology 2003, 98:815-822.

56. Vamvakas EC, Carven JH: Length of storage of transfused red cells and postoperative morbidity in patients undergoing coronary artery bypass graft surgery. Transfusion 2000, 40:101-109. 
57. Sanders J, Patel S, Cooper J, Berryman J, Farrar D, Mythen M, Montgomery HE: Red blood cell storage is associated with length of stay and renal complications after cardiac surgery. Transfusion 2011, 51:2286-2294.

58. Keller ME, Jean R, LaMorte WW, Millham F, Hirsch E: Effects of age of transfused blood on length of stay in trauma patients: a preliminary report. J Trauma 2002, 53:1023-1025.

59. Vamvakas EC, Carven JH: Transfusion and postoperative pneumonia in coronary artery bypass graft surgery: effect of the length of storage of transfused red cells. Transfusion 1999, 39:701-710.

60. Andreasen JJ, Dethlefsen C, Modrau IS, Baech J, Schonheyder HC, Moeller JK, Johnsen SP: Storage time of allogeneic red blood cells is associated with risk of severe postoperative infection after coronary artery bypass grafting. Eur J Cardiothorac Surg 2011, 39:329-334.

61. Edna TH, Bjerkeset T: Association between transfusion of stored blood and infective bacterial complications after resection for colorectal cancer. Eur J Surg 1998, 164:449-456.

62. Mynster T, Nielsen HJ: The impact of storage time of transfused blood on postoperative infectious complications in rectal cancer surgery. Danish RANX05 Colorectal Cancer Study Group. Scand J Gastroenterol 2000, 35:212-217.

63. Vandromme MJ, McGwin G Jr, Marques MB, Kerby JD, Rue LW, Weinberg JA: Transfusion and pneumonia in the trauma intensive care unit: an examination of the temporal relationship. J Trauma 2009, 67:97-101.

64. Offner PJ, Moore EE, Biffl WL, Johnson JL, Silliman CC: Increased rate of infection associated with transfusion of old blood after severe injury. Arch Surg 2002, 137:711-716.

65. Juffermans NP, Vlaar AP, Prins DJ, Goslings JC, Binnekade JM: The age of red blood cells is associated with bacterial infections in critically ill trauma patients. Blood Transfus 2012, 10:290-295.

66. Taylor RW, O'Brien J, Trottier SJ, Manganaro L, Cytron M, Lesko MF, Arnzen K, Cappadoro C, Fu M, Plisco MS, Sadaka FG, Veremakis C: Red blood cell transfusions and nosocomial infections in critically ill patients. Crit Care Med 2006, 34:2302-2308.

67. Juffermans NP, Prins DJ, Vlaar AP, Nieuwland R, Binnekade JM: Transfusionrelated risk of secondary bacterial infections in sepsis patients: a retrospective cohort study. Shock 2011, 35:355-359.

68. Zallen G, Offner PJ, Moore EE, Blackwell J, Ciesla DJ, Gabriel J, Denny C, Silliman CC: Age of transfused blood is an independent risk factor for postinjury multiple organ failure. Am J Surg 1999, 178:570-572.

69. Weiskopf RB, Feiner J, Toy P, Twiford J, Shimabukuro D, Lieberman J, Looney MR, Lowell CA, Gropper MA: Fresh and stored red blood cell transfusion equivalently induce subclinical pulmonary gas exchange deficit in normal humans. Anesth Analg 2012, 114:511-519.

70. Gajic O, Rana R, Mendez JL, Rickman OB, Lymp JF, Hubmayr RD, Moore SB: Acute lung injury after blood transfusion in mechanically ventilated patients. Transfusion 2004, 44:1468-1474.

71. Marik PE, Sibbald WJ: Effect of stored-blood transfusion on oxygen delivery in patients with sepsis. JAMA 1993, 269:3024-3029.

72. Fernandes CJ Jr, Akamine N, De Marco FV, De Souza JA, Lagudis S, Knobel E: Red blood cell transfusion does not increase oxygen consumption in critically ill septic patients. Crit Care 2001, 5:362-367.

73. Walsh TS, McArdle F, McLellan SA, Maciver C, Maginnis M, Prescott RJ, McClelland DB: Does the storage time of transfused red blood cells influence regional or global indexes of tissue oxygenation in anemic critically ill patients? Crit Care Med 2004, 32:364-371.

74. Marik P: Does the age of blood matter? Crit Care Med 2004, 32:1442-1443.

75. Sakr Y, Chierego M, Piagnerelli M, Verdant C, Dubois MJ, Koch M, Creteur J, Gullo A, Vincent JL, De Backer D: Microvascular response to red blood cell transfusion in patients with severe sepsis. Crit Care Med 2007, 35:1639-1644.

76. Yuruk K, Milstein DM, Bezemer R, Bartels SA, Biemond BJ, Ince C: Transfusion of banked red blood cells and the effects on hemorrheology and microvascular hemodynamics in anemic hematology outpatients. Transfusion 2012, doi: 10.1111/j.15372995.2012.03905

77. Leal-Noval SR, Munoz-Gomez M, Arellano-Orden V, Marin-Caballos A, mayaVillar R, Marin A, Puppo-Moreno A, Ferrandiz-Millon C, Flores-Cordero JM, Murillo-Cabezas F: Impact of age of transfused blood on cerebral oxygenation in male patients with severe traumatic brain injury. Crit Care Med 2008, 36:1290-1296.

78. Netzer G, Dutton RP, Hess JR: Right data, wrong conclusions. Crit Care Med 2008, 36:1383-1384.

79. Kiraly LN, Underwood S, Differding JA, Schreiber MA: Transfusion of aged packed red blood cells results in decreased tissue oxygenation in critically injured trauma patients. J Trauma 2009, 67:29-32

80. Santora RJ, Moore FA: Monitoring trauma and intensive care unit resuscitation with tissue hemoglobin oxygen saturation. Crit Care 2009, Suppl 5: S10.

81. Creteur J, Neves AP, Vincent JL: Near-infrared spectroscopy technique to evaluate the effects of red blood cell transfusion on tissue oxygenation. Crit Care 2009, , Suppl 5: S11.

82. Berra L, Coppadoro A, Yu B, Lei C, Spagnolli E, Steinbicker AU, Bloch KD, Lin T, Sammy FY, Warren HS, Fernandez BO, Feelisch M, Dzik WH, Stowell CP, Zapol WM: Transfusion of stored autologous blood does not alter reactive hyperemia index in healthy volunteers. Anesthesiology 2012, 117:56-63.

83. Roberson RS, Lockhart E, Shapiro NI, Bandarenko N, McMahon TJ, Massey MJ, White WD, Bennett-Guerrero E: Impact of transfusion of autologous 7- versus 42-day-old AS-3 red blood cells on tissue oxygenation and the microcirculation in healthy volunteers. Transfusion 2012, 52:2459-2464.

84. Kopterides P, Theodorakopoulou M, Nikitas N, llias I, Vassiliadi DA, Orfanos SE, Tsangaris I, Maniatis NA, Tsantes AE, Travlou A, Dimitriadis G, Armaganidis A, Ungerstedt U, Dimopoulou I: Red blood cell transfusion affects microdialysis-assessed interstitial lactate/pyruvate ratio in critically ill patients with late sepsis. Intensive Care Med 2012, 38:1843-1850

85. Katsios C, Griffith L, Spinella P, Lacroix J, Crowther M, Hebert P, Meade M, Geerts W, Rabbat C, Cook D: Red blood cell transfusion and increased length of storage are not associated with deep vein thrombosis in medical and surgical critically ill patients: a prospective observational cohort study. Crit Care 2011, 15:R263.

86. Naidech AM, Liebling SM, Duran IM, Ault ML: Packed red blood cell age does not impact adverse events or outcomes after subarachnoid haemorrhage. Transfus Med 2011, 21:130-133.

87. Wasser MN, Houbiers JG, D'Amaro J, Hermans J, Huysmans HA, van Konijnenburg GC, Brand A: The effect of fresh versus stored blood on post-operative bleeding after coronary bypass surgery: a prospective randomized study. Br J Haematol 1989, 72:81-84.

88. Weiskopf RB, Feiner J, Hopf H, Lieberman J, Finlay HE, Quah C, Kramer JH, Bostrom A, Toy P: Fresh blood and aged stored blood are equally efficacious in immediately reversing anemia-induced brain oxygenation deficits in humans. Anesthesiology 2006, 104:911-920.

89. Cata JP, Klein EA, Hoeltge GA, Dalton JE, Mascha E, O'Hara J, Russell A, Kurz A, Ben-Elihayhu S, Sessler DI: Blood storage duration and biochemical recurrence of cancer after radical prostatectomy. Mayo Clin Proc 2011, 86:120-127.

90. Weinberg JA, Barnum SR, Patel RP: Red blood cell age and potentiation of transfusion-related pathology in trauma patients. Transfusion 2011, 51:867-873.

91. Pereira A: Will clinical studies elucidate the connection between the length of storage of transfused red blood cells and clinical outcomes? An analysis based on the simulation of randomized controlled trials. Transfusion 2013, 53:34-40.

92. Middelburg RA, van de Watering LM, van der Bom JG: Blood transfusions: good or bad? Confounding by indication, an underestimated problem in clinical transfusion research. Transfusion 2010, 50:1181-1183.

93. Jenkins PV, O'Donnell JS: ABO blood group determines plasma von Willebrand factor levels: a biologic function after all? Transfusion 2006, 46:1836-1844.

94. Ioannidis JP, Lau J: Pooling research results: benefits and limitations of meta-analysis. Jt Comm J Qual Improv 1999, 25:462-469.

95. Flegel WA: Fresh blood for transfusion: how old is too old for red blood cell units? Blood Transfus 2012, 10:247-251.

96. Heddle NM, Cook RJ, Arnold DM, Crowther MA, Warkentin TE, Webert KE, Hirsh J, Barty RL, Liu Y, Lester C, Eikelboom JW: The effect of blood storage duration on in-hospital mortality: a randomized controlled pilot feasibility trial. Transfusion 2012, 52:1203-1212. 
97. Aubron C, Syres G, Nichol A, Bailey M, Board J, Magrin G, Murray L, Presneill J, Sutton J, Vallance S, Morrison S, Bellomo R, Cooper DJ: A pilot feasibility trial of allocation of freshest available red blood cells versus standard care in critically ill patients. Transfusion 2012, 52:1196-1202.

98. Lacroix J, Hebert P, Fergusson D, Tinmouth A, Blajchman MA, Callum J, Cook D, Marshall JC, Mclntyre L, Turgeon AF: The Age of Blood Evaluation (ABLE) randomized controlled trial: study design. Transfus Med Rev 2011, 25:197-205.

99. Steiner ME, Assmann SF, Levy JH, Marshall J, Pulkrabek S, Sloan SR, Triulzi D, Stowell CP: Addressing the question of the effect of RBC storage on clinical outcomes: the Red Cell Storage Duration Study (RECESS) (Section 7). Transfus Apher Sci 2010, 43:107-116.

100. Schulman Cl, Nathe K, Brown M, Cohn SM: Impact of age of transfused blood in the trauma patient. J Trauma 2002, 52:1224-1225.

101. Hebert PC, Chin-Yee I, Fergusson D, Blajchman M, Martineau R, Clinch J, Olberg B: A pilot trial evaluating the clinical effects of prolonged storage of red cells. Anesth Analg 2005, 100:1433-1438.

102. Bennett-Guerrero E, Stafford-Smith M, Waweru PM, Bredehoeft SJ, Campbell ML, Haley NR, Phillips-Bute B, Newman MF, Bandarenko N: A prospective, double-blind, randomized clinical feasibility trial of controlling the storage age of red blood cells for transfusion in cardiac surgical patients. Transfusion 2009, 49:1375-1383.

103. Fogh-Andersen N, Mogensen F: On the safety of using stored bank blood for chronic hemodialysis patients. Transfusion 1984, 24:505-507.

104. Luten M, Roerdinkholder-Stoelwinder B, Schaap NP, De Grip WJ, Bos HJ, Bosman GJ: Survival of red blood cells after transfusion: a comparison between red cells concentrates of different storage periods. Transfusion 2008, 48:1478-1485.

105. Pieracci FM, Moore EE, Chin T, Townsend N, Gonzalez E, Burlew CC, Barnett CC Jr: The age of transfused blood predicts hematocrit response among critically ill surgical patients. Am J Surg 2012, 204:269-273.

106. Hoh H, Umpleby H, Cooper A, Taylor I: Recurrence of colorectal cancer and perioperative blood transfusion. Is blood storage time important? Dis Colon Rectum 1990, 33:127-130.

107. Lebiedz P, Glasmeyer S, Hilker E, Yilmaz-Neuhaus A, Karaboutas T, Reinecke H, Sibrowski W, Nofer JR: Influence of red blood cell storage time on clinical course and cytokine profile in septic shock patients. Transfus Med Hemother 2012, 39:271-276.

108. Zubair AC: Clinical impact of blood storage lesions. Am J Hematol 2010, 85:117-122.

109. Roback JD: Vascular effects of the red blood cell storage lesion. Hematology Am Soc Hematol Educ Program 2011, 2011:475-479.

110. Reynolds JD, Ahearn GS, Angelo M, Zhang J, Cobb F, Stamler JS: Snitrosohemoglobin deficiency: a mechanism for loss of physiological activity in banked blood. Proc Natl Acad Sci USA 2007, 104:17058-17062.

111. Kay MM, Flowers N, Goodman J, Bosman G: Alteration in membrane protein band 3 associated with accelerated erythrocyte aging. Proc Natl Acad Sci USA 1989, 86:5834-5838.

112. Grimshaw K, Sahler J, Spinelli SL, Phipps RP, Blumberg N: New frontiers in transfusion biology: identification and significance of mediators of morbidity and mortality in stored red blood cells. Transfusion 2011, 51:874-880.

113. Basora M, Pereira A, Soriano A, Martinez-Pastor JC, Sanchez-Etayo G, Tio M, Salazar F: Allogeneic blood transfusion does not increase the risk of wound infection in total knee arthroplasty. Vox Sang 2010, 98:124-129.

doi:10.1186/cc12600

Cite this article as: Lelubre and Vincent: Relationship between red cell storage duration and outcomes in adults receiving red cell transfusions: a systematic review. Critical Care 2013 17:R66.

\section{Submit your next manuscript to BioMed Central and take full advantage of:}

- Convenient online submission

- Thorough peer review

- No space constraints or color figure charges

- Immediate publication on acceptance

- Inclusion in PubMed, CAS, Scopus and Google Scholar

- Research which is freely available for redistribution

Submit your manuscript at www.biomedcentral.com/submit
Biomed Central 